\title{
DELINEATING WETLANDS IN SERPENTINITIC SOILS
}

\author{
A Thesis \\ presented to \\ the Faculty of California Polytechnic State University, \\ San Luis Obispo
}

\author{
In Partial Fulfillment \\ of the Requirements for the Degree
}

Master of Science in Agriculture with a specialization in Soil Science

by

Ariel Namm

August 2014 
(C) 2014

Ariel Namm

ALL RIGHTS RESERVED 
TITLE:

AUTHOR:

DATE SUBMITTED:

COMMITTEE CHAIR:

COMMITTEE MEMBER:

COMMITTEE MEMBER:
Delineating Wetlands in Serpentinitic Soils

Ariel Namm

August 2014

Dr. Karen Vaughan, PhD

Assistant Professor in Natural Resources

Management and Environmental Sciences

Department

Dr. Chip Appel, PhD

Assistant Professor in Natural Resources

Management and Environmental Sciences

Department

Dr. Matt Ritter, PhD

Associate Professor in Biological Sciences

Department 


\section{ABSTRACT \\ Delineating Wetlands in Serpentinitic Soils}

Ariel Namm

Wetlands serve an important ecological and functional role in the environment. In order to protect wetlands from degradation, the determination of wetland hydrology, hydrophytic vegetation, and hydric soils is necessary. Soils formed from serpentine parent material on hillside slump blocks do not meet any of the current morphological Field Indicators of Hydric Soils. Although these areas seem to be wetlands based on wetland hydrology and hydrophytic vegetation, there is no approved hydric soil indicator that includes the properties exhibited by serpentinitic soils on these landscapes. The objectives of this research were: (1) to examine soil chemical, physical, and morphological properties to determine if they meet the criteria for hydric soils; and (2) to develop a new test Field Indicator of Hydric Soil for use in soils formed in serpentinitic parent materials along the Central Coast of California. Two research sites in Poly Canyon, north of California Polytechnic State University in San Luis Obispo, were instrumented with Indicator of Reduction in Soil (IRIS) tubes over a three month period to measure the amount of Fe reduction in the soil profiles to a depth of $50 \mathrm{~cm}$. The results of the IRIS tube analyses displayed anaerobic conditions persisting for longer than 14 days during the growing season; therefore, these soils are in fact hydric. The development of a new test Field Indicator of Hydric Soil is necessary. Preliminarily, the following is proposed as a new test indicator: soils formed in serpentine parent material occurring on a slump block landforms with a layer at least $10 \mathrm{~cm}$ (4 inches) thick, no chroma color with a value of 2 or less, and few or less concentrations. The layer is entirely within $30 \mathrm{~cm}$ (12 inches) of the soil surface. Further research to test this new field indicator includes an additional research site and a year of supplementary data.

Abbreviations:

California Polytechnic State University (Cal Poly)

Environmental Protection Agency (EPA)

Hydric Soil Technical Standards (HSTS)

Indicator of Reduction in Soil (IRIS)

National Technical Committee for Hydric Soils (NTCHS)

Prevalence Index (PI)

Polyvinyl Chloride (PVC) 


\section{ACKNOWLEDGMENTS}

My research would not have been possible if it were not for my advisor and committee chair Dr. Karen Vaughan. I wish to express my sincere gratitude for her friendship and professional support.

I am fortunate to have had the knowledge of my graduate committee, Drs. Chip Appel and Matt Ritter. Chip, thank you for introducing me to the field and sparking my love of soils.

I would like to thank the Natural Resources and Environmental Sciences (NRES) Department technician Craig Stubler for his help with much of the laboratory procedures and to the undergrads of the NRES Department for helping dig holes and play in the mud on a weekend. A special thank you to my field assistant, Scott Pensky, for his weekly dedication and positive attitude to the project.

Lastly, I am very grateful to have been blessed with a devoted and loving family. You have given me the confidence and support in my pursuit of both professional knowledge and personal development. 


\section{DEDICATION}

For my mom. A role model for life and for women in sciences.

Without your patience and constant support, this research would not have been possible. 


\section{TABLE OF CONTENTS}

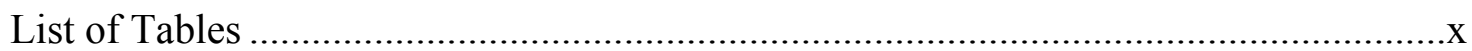

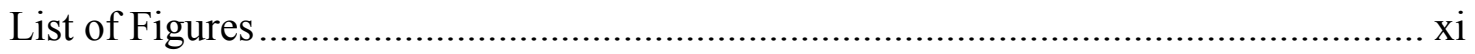

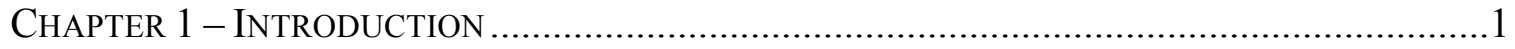

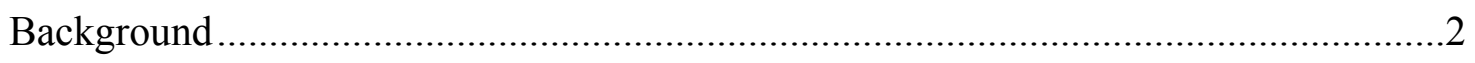

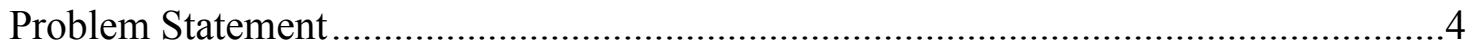

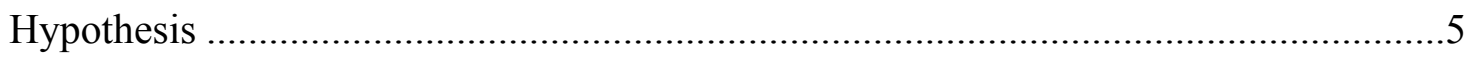

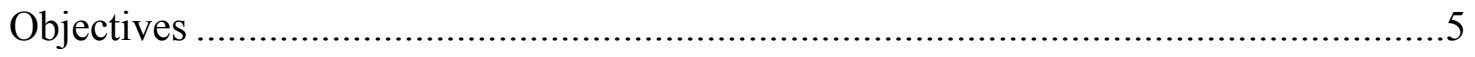

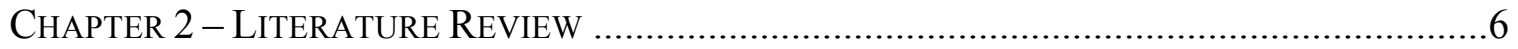

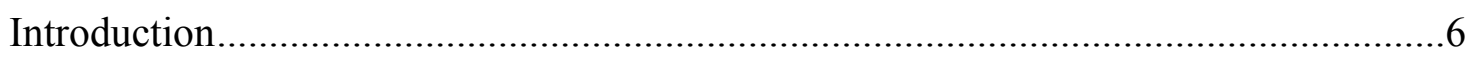

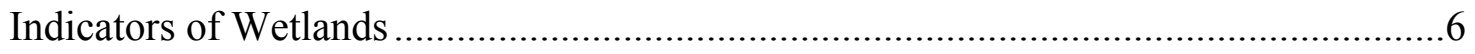

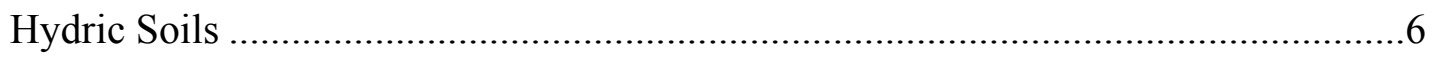

Problematic Wetland Soils......................................................................

Reduction and Oxidation ......................................................................

Indicator of Reduction in Soil (IRIS) Tubes..............................................10

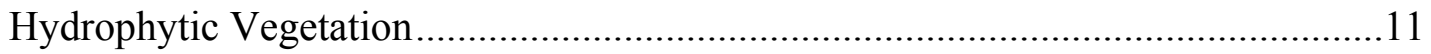

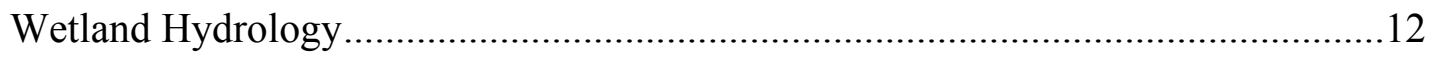

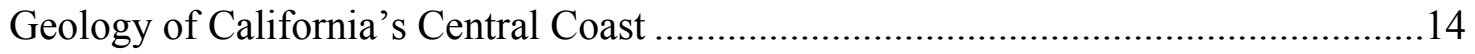

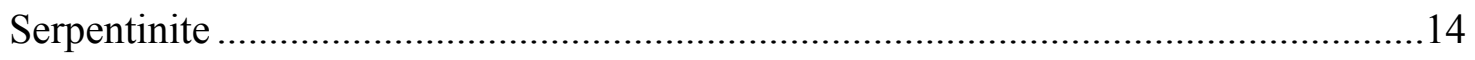

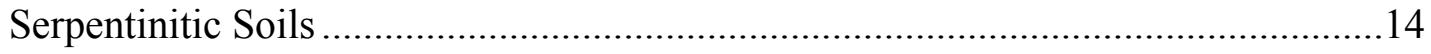

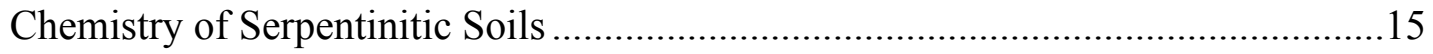

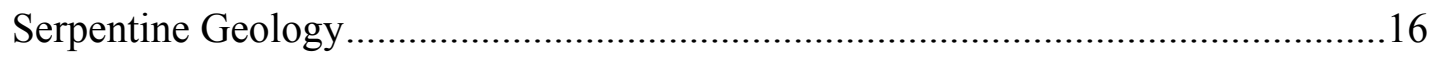

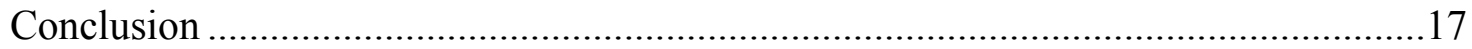


CHAPTER 3 - HYDRIC SOIL EVALUATION USING IRIS TUBES.............................................18

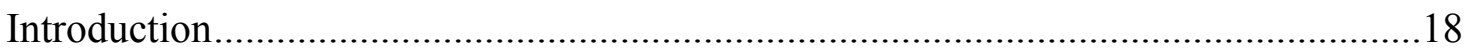

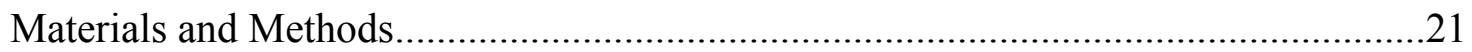

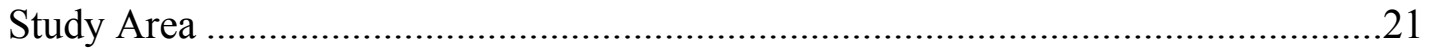

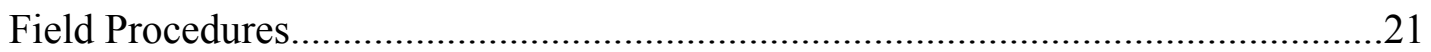

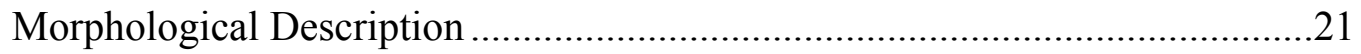

Preparation and Installation of IRIS Tubes........................................................21

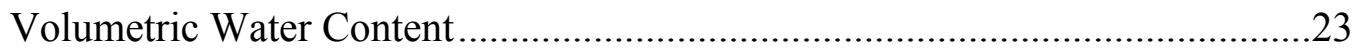

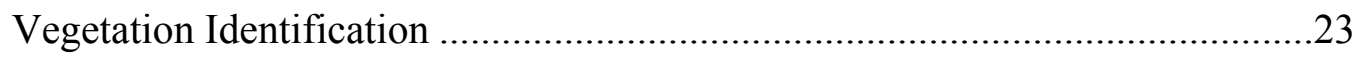

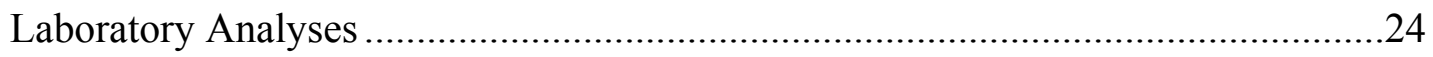

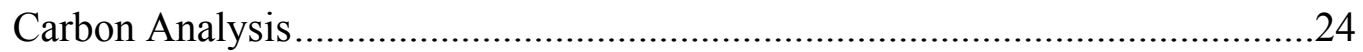

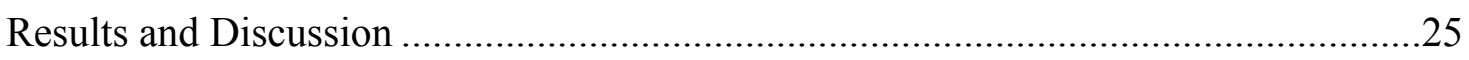

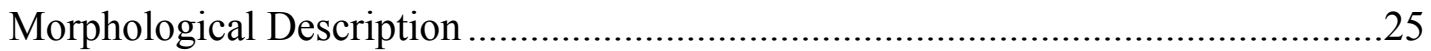

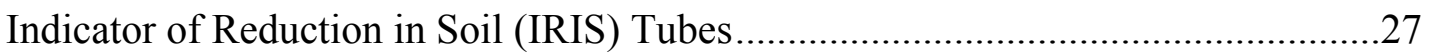

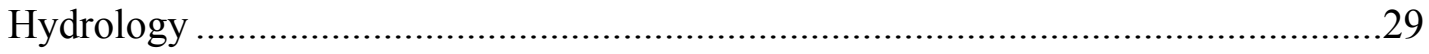

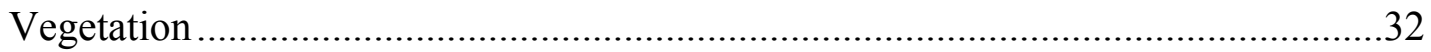

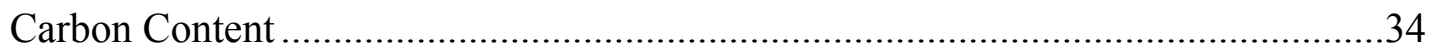

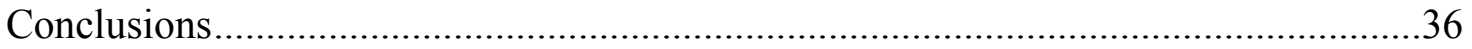

CHAPTER 4 - Morphology OF SERPENTINITIC Hydric SoILS .............................................

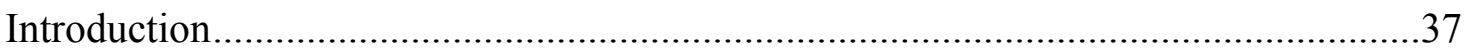

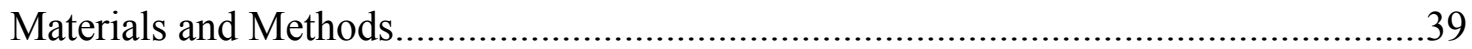

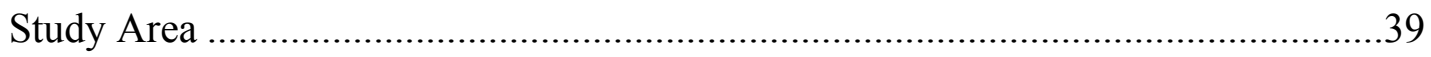

Field Procedures....................................................................................................... 
Morphological Description and Bulk Density Clod Collection

Laboratory Analyses

Bulk Density ..........................................................................................4 40

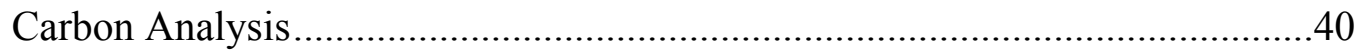

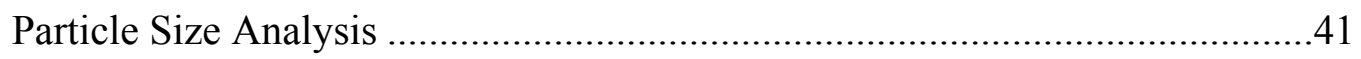

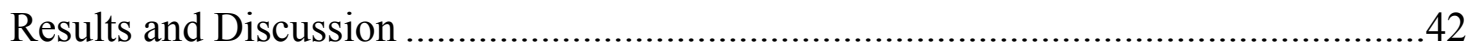

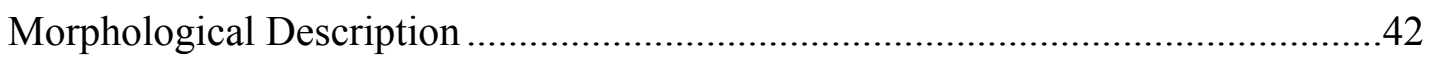

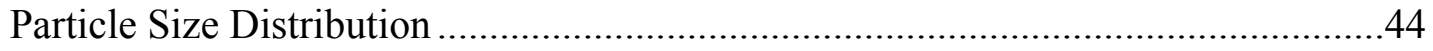

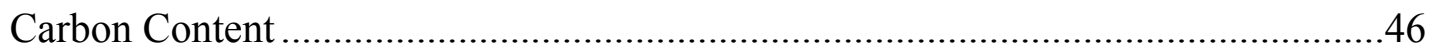

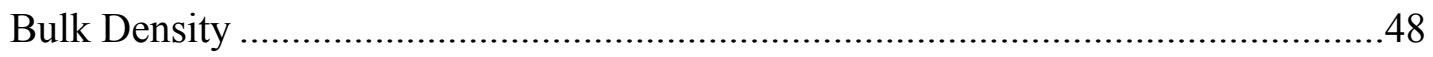

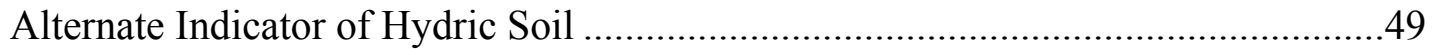

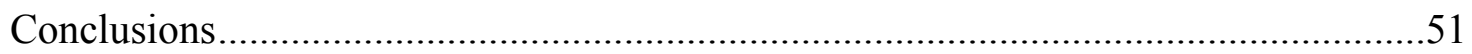

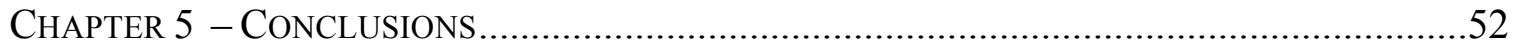

CHAPTER 6 - FUTURE CONSIDERATIONS ...................................................................5

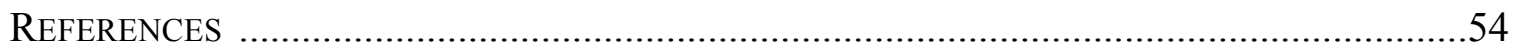

APPENDICES

A. Particle Size Analysis and Bulk Density Data ...................................57

B. Soil Volumetric Water Content ......................................................58

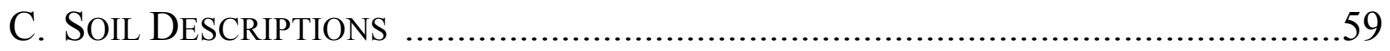

D. Soil Profile Photos .........................................................................60 


\section{LIST OF TABLES}

Table 2-1. Vegetation indicator categories for wetland delineation (U.S. Army Corps

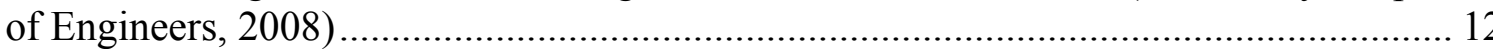

Table 3-1a. Description of soil at south research site (all colors were recorded moist unless otherwise noted)

Table 3-1b. Description of soil at north research site (all colors were recorded moist unless otherwise noted)

Table 3-2a. Vegetation analysis using the prevalence index for the south research site

Table 3-2b. Vegetation analysis using the prevalence index for the north research site.

Table 4-1a. Description of soil at south research site (all colors were recorded moist unless otherwise noted).

Table 4-1b. Description of soil at north research site (all colors were recorded moist unless otherwise noted). 


\section{LIST OF FIGURES}

Figure 1-1. Location of research sites in Poly Canyon, north of California

Polytechnic (Cal Poly) State University in San Luis Obispo

Figure 1-2. Diagram of rotational earth movement that forms slump block geology (Ministry of Energy and Mines, 2013)

Figure 2-1. Eh-pH phase diagram for the succession of reducing electron reactions occurring in hydric soil conditions (Craft et al., 2001).

Figure 3-1a. Average percentage of oxidation and reduction (iron oxide paint removal) from the top $15 \mathrm{~cm}$ section of the tubes using Indicator of Reduction in Soil (IRIS) tubes removed in February and March 2014 at the south research site ..... 28

Figure 3-1b. Average percentage of oxidation and reduction (iron oxide paint removal) from the top $15 \mathrm{~cm}$ section of the tubes using Indicator of Reduction in Soil (IRIS) tubes removed in February and March 2014 at the north research site..... 28

Figure 3-2a. Soil volumetric water content measured at 10, 20, 30, 40, and $50 \mathrm{~cm}$ below the soil surface from January to March 2014 at the south research site 30

Figure 3-2b. Soil volumetric water content measured at 10, 20,30, 40, and $50 \mathrm{~cm}$ below the soil surface from January to March 2014 at the north research site. 31

Figure 3-3. Total carbon percentage for soils at the north and south research sites....... 35

Figure 4-1. Total clay percentage for soils at the north and south research sites.......... 45

Figure 4-2. Total carbon percentage for soils at the north and south research sites....... 47

Figure 4-3. Diagram of new test indicator for hydric soils occurring on serpentinitic parent material and slump block geology. 50 


\section{CHAPTER 1 - INTRODUCTION}

Wetlands are areas that are saturated by surface and/or groundwater at a frequency and duration long enough for anaerobic conditions to form (Mitsch et al., 2009). Plant and animal species in wetlands are adapted to reduced levels of oxygen during periodic or seasonal flooding and are also able to survive during the dry season when oxygen is present again (Craft et al., 2001).

Wetlands are not only unique environments, but sensitive environments as well. Under Section 404 of the Clean Water Act, an area must be delineated a wetland in order to receive regulatory protection (U.S. Army Corps of Engineers, 2008). Delineation is based on a three-factor analysis, including the study of the hydrology, vegetation, and soil morphology.

Certain soil morphological features form as a result of the reduced conditions, which are used in the field to determine if a soil is hydric. These features include low chroma, gley colors, and thick, dark organic rich surface horizons. However, areas that meet the standards for wetland hydrology and hydrophytic vegetation sometimes do not meet the standards for hydric soils but are still considered hydric (Berkowitz and Sallee, 2011). These types of soils are often referred to as 'problematic' hydric soils. Alternative field instrumentation, including Indicator of Reduction in Soil (IRIS) Tubes, is necessary to determine the percent reduction to determine if the problematic soil is indeed a hydric soil (Rabenhorst, 2008).

This research investigates two problematic soils in Poly Canyon, north of California Polytechnic State University (Cal Poly) in San Luis Obispo, formed in serpentintic parent material situated on a slump block. These sites meet standards for 
wetland hydrology and hydophytic vegetation but lack morphological features for them to meet a current Field Indicator of Hydric Soil.

\section{Background}

The research sites are located within Poly Canyon, north of California Polytechnic State University Campus in San Luis Obispo, California (Fig. 1-2). Land use in the area is mainly recreation including hiking and biking trails for students and community members as well as grazing land for cattle and horses. The research sites are hypothesized to be wetlands and were chosen for comparison due to their similar soil morphology, hydrology, geology, and landscape position.

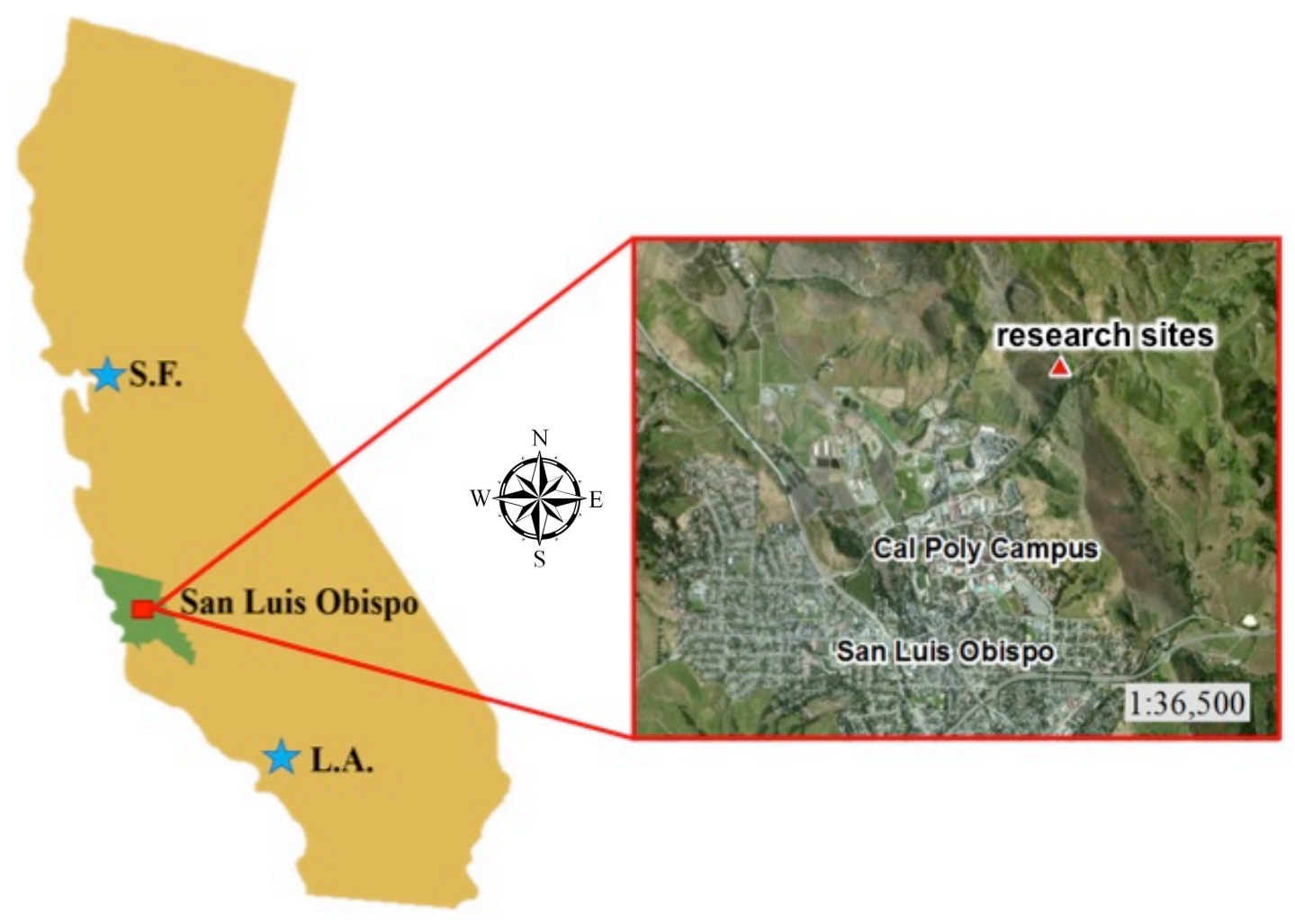

Figure 1-1. Location of research sites in Poly Canyon, north of California Polytechnic (Cal Poly) State University in San Luis Obispo. 
The morphological descriptions of the research sites do not meet a Field Indicator of Hydric Soils established by the National Technical Committee for Hydric Soils (Vasilas et al., 2010). However, not meeting technical requirements does not disqualify this area from being delineated as a wetland. The standards often change as new research and findings are discovered each year. Soils that do not meet the existing standards for hydric soils but are suspected of being hydric are simply known as 'problematic'.

A tool used by soil scientists to investigate problematic hydric soils is Indicator of Reduction in Soil (IRIS) tubes. Indicator of Reduction in Soil tubes are polyvinyl chloride tubes painted with synthetic iron oxide paint. The tubes are inserted into a soil for a specified time and removed for visual analysis. For a soil to be considered hydric there must be at least $30 \%$ of iron reduction or paint removal within $15 \mathrm{~cm}$ of the soil surface for 3 of the 5 tubes (Rabenhorst and Burch, 2006).

The formation of the research sites at Poly Canyon resulted from a landslide that created a slump of soil at the lower backslope of a hill known as a slump block (Fig. 1-3). The rotational movement of the earth that forms the soil at the research sites contributes to the unique disturbed soil morphology.

The results of this earth movement also created a tributary that channels water into the slump research sites when water is present. The areas receive water from these waterways as well as direct infiltration from seasonal precipitation. Large earth movements and a hummocky topography are typical of this area due to its proximity to the San Andres Fault, shallow depth to bedrock, and serpentinitic composition of the parent material (Alexander et al., 2007). 


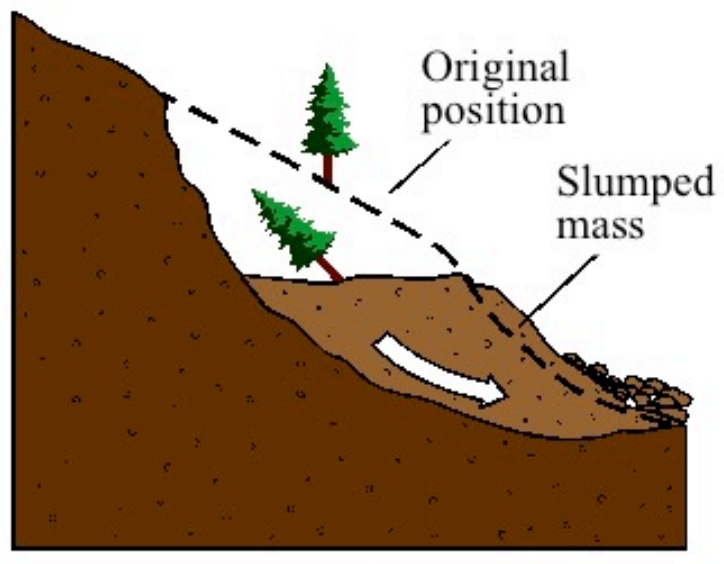

Figure 1-2. Diagram of rotational earth movement that forms slump block geology (Ministry of Energy and Mines, 2013).

The research sites are located on serpentine rock. Serpentine rock has a unique chemical makeup that affects the function of soil as it weathers. Serpentine parent materials are similar to that of ultramafic parent materials, which have a high concentration of $\mathrm{Mg}$ and low concentrations of plant productive elements such as $\mathrm{Si}, \mathrm{Ca}$, $\mathrm{K}$, and $\mathrm{P}$. Another important aspect of serpentine soils is the increased susceptibility to erosion and colluvium deposits. This is largely due to the serpentinite and peridotite parent materials, which generally consist of unstable, disintegrated bedrock (Alexander et al., 2007).

\section{Problem Statement}

The research sites display wetland hydrology and have hydrophytic vegetation present; however, the soil morphological descriptions revealed that the soils do not meet any of the existing the Field Indicators of Hydric Soils (Vasilas et al., 2010). 


\section{Hypothesis}

Despite the lack of appropriate Field Indicator, this soil qualifies as a wetland based on existing field conditions as well as physical and chemical analyses.

\section{Objectives}

The objectives of this research were (1) to examine soil chemical, physical, and morphological properties to determine whether or not this problematic soil meets the criteria for hydric soils; and (2) to develop a new test Field Indicator of Hydric Soil for use in soils formed in serpentinitic parent materials along the Central Coast of California. 


\section{CHAPTER 2 - LITERATURE REVIEW}

\section{Introduction}

Wetlands are defined as areas that are saturated by surface and/or groundwater at a frequency and duration long enough for anaerobic conditions to form. Wetlands in the United States comprise $400,000 \mathrm{~km}^{2}$, which is only half of the natural wetlands that once existed when European settlement first began (Brady and Weil, 2010). Today, the importance of wetland areas is well understood and this understanding is growing as new research of wetland areas is being conducted around the world.

In order to protect wetlands, it is important to delineate these environments from environments that seem similar. Therefore, three key features that all wetlands share have been thoroughly studied and documented including soils, vegetation, and hydrology to distinguish areas for protection (U.S. Army Corps of Engineers, 2008). This chapter will discuss these three key features as well as California's geology and serpentinitic geomorphology.

\section{Indicators of Wetlands}

$\underline{\text { Hydric Soils }}$

Hydric soils require the presence of soil microbes, which are vital to decomposition in wetland environments. Decomposition of organic matter by microorganisms is regulated by oxygen, temperature, $\mathrm{pH}$, nutrients, availability of terminal electron acceptors, and organic matter quality. Other field factors to consider when estimating rates of decomposition of organic matter includes soil texture, available 
water holding capacity, runoff rates, topography, and fauna of the soil (Vaughan et al., 2009).

The factors that limit the development of hydric soils include high acidity, low organic matter, cold temperatures, and low iron presence. These factors are directly correlated with conditions that limit efficient functioning of microorganisms. Lower temperatures slow microbial transfer rates of electrons and lower the redox potential of soil. In contrast, greater carbon presence provides an energy source for the microorganisms, which leads to a rapid reduction of the soil environment (Berkowitz and Sallee, 2011).

\section{Problematic Wetland Soils}

Hydric soils are typically delineated in the field and supported later by laboratory data. The organization responsible for standardization of Field Indicator of Hydric Soils is the National Technical Committee for Hydric Soils (Vasilas et al., 2010). The standards are designed to be proof-positive and change periodically as more research is added and new discoveries by soil scientists are made. Morphological indicators of hydric soils include accumulation of organic matter, redox concentrations, and redox depletions including color changes as a result of reduction and translocation of redox sensitive species (Berkowitz and Sallee, 2011).

Preliminary determination of hydric soils can be done by excavating a soil pit to $50 \mathrm{~cm}$ and observing the soil features. Thick, dark surface layers indicate an accumulation of organic matter. Redoximorphic features seen in hydric soils include contrasting colors of redox depletions or reduced iron and zones of reddish iron that 
result in unique mottling. Similar features can be seen in the lower horizons of upland soils but are still not considered wetlands because there is no further evidence of a wetland environment (Brady and Weil, 2010).

A site that is inconsistent with approved Field Indicator of Hydric Soils is considered a 'problematic' soil. Problematic soils do not have common hydric soil morphologies but may still be considered a wetland. Development of new Field Indicators of Hydric Soils requires an integrated approach of both field and laboratory research of the problematic soils (Berkowitz and Sallee, 2011).

In order to determine if a problematic soil is indeed hydric, the soil must still be reducing despite the lack of redoximorphic features in the soil profile. A method for determining reduction and oxidation includes the investigation into the relationship between redox potential and $\mathrm{pH}$ through the use of a voltmeter and a $\mathrm{pH}$ meter. Another method measures the reduction of iron from polyvinyl chloride (PVC) tubes known as Indicator of Reduction in Soil (IRIS) tubes, which have been coated with iron oxide paint (Rabenhorst and Burch, 2006).

\section{Reduction and Oxidation}

During metabolic oxidation processes, soil microorganisms produce electrons, which require an electron acceptor. Due to the absence of oxygen in an anaerobic environment, microorganisms have adapted to use other elements as electron acceptors. The sequence of electron acceptors is determined by redox potential (Eh) (Fig. 2-1). Elements with the greatest redox potential are utilized first followed by the element with the next greatest redox potential and so on. In order for reduction to occur, the following 
conditions must be present: saturation with stagnant water, presence of microorganisms, a supply of carbon, and suitable soil temperatures (Vaughan et al., 2009).

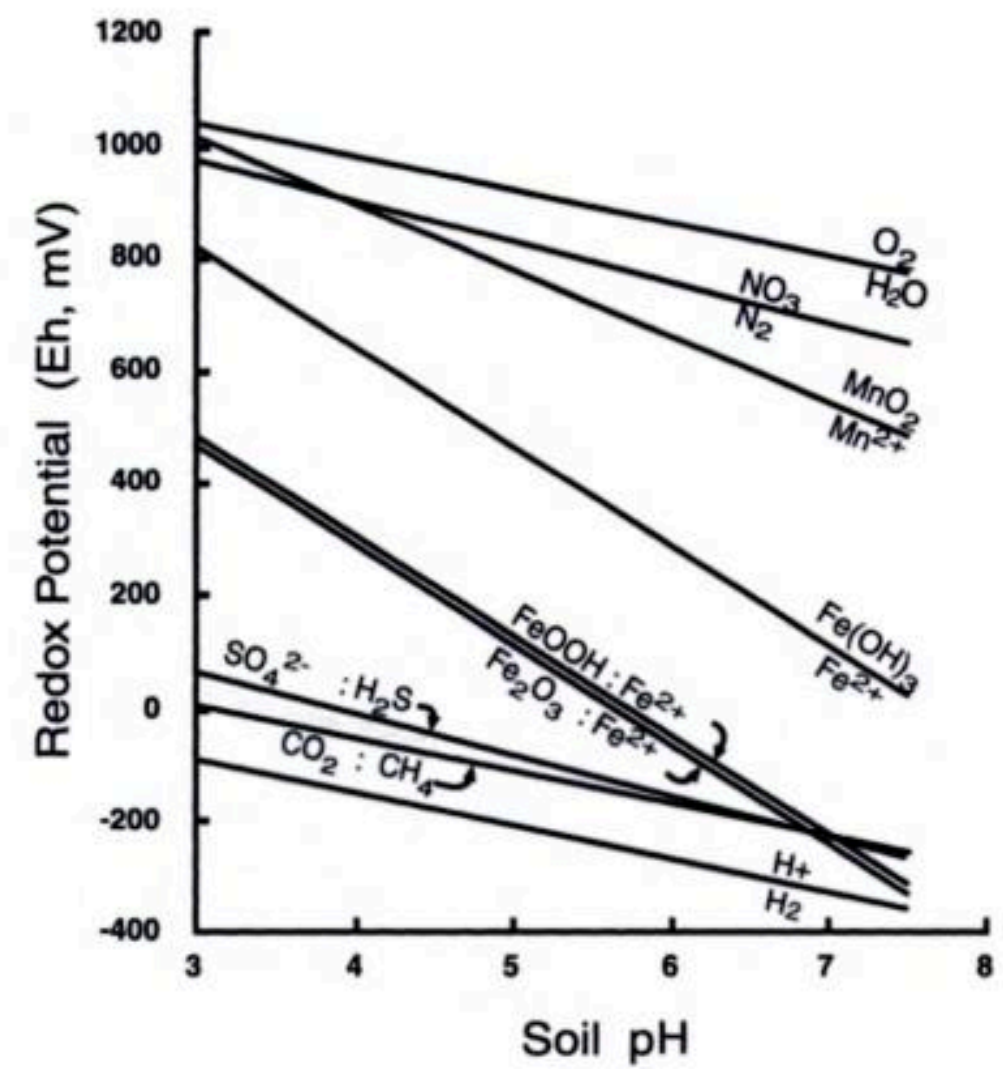

Figure 2-1. Eh-pH phase diagram for the succession of reducing electron reactions occurring in hydric soil conditions (Craft et al., 2001).

Reduced and oxidized conditions in the soil have been shown to have an effect on many different aspects of saturated soil processes. Therefore, the accurate and precise measurement of redox potential is important to further research in soil science. The measurement of redox potential requires a sensor electrode, typically made of platinum wire, and a reference electrode inserted into the soil. Redox potential is the recordings of voltage between the sensor electrode and the reference electrode. The voltage occurs during the oxidation and reduction process as a result of exchanging electrons between a 
redox couple, such as ferric and ferrous iron. Greater variation of redox potential occurs in soils with wider fluctuations of wet and dry conditions (Fiedler et al, 2007).

Due to the complexities of redox potentials, there are several complications with the measurement process. One of the most common issues is the dominant nature of the ferric and ferrous iron couple. This dominance contributes to complications when measuring other redox couples. Another major issue with measuring redox is the sensitive field equipment, which can lead to problems such as inaccurate results (Fiedler et al., 2007).

\section{Indicator of Reduction in Soil (IRIS) Tubes}

Under anaerobic conditions, soil microorganisms deplete dissolved oxygen as they oxidize soil organic matter. Once oxygen has been completely depleted from the soil pores, the microbes require a different element as an electron acceptor such as $\mathrm{Fe}^{3+}$. The reduction of $\mathrm{Fe}^{3+}$ is used to analyze IRIS tubes because of its distinct reddish orange color and higher redox potential relative to S (Fig. 2-1) (Mitsch et al., 2009).

Indicator Reduction In Soil tubes are constructed by coating polyvinyl chloride (PVC) tubes with reddish orange iron oxide paint (Rabenhorst, 2008). During dry, oxidized soil conditions, the red iron oxide coating is left undisturbed by the microbes. In saturated conditions, the $\mathrm{Fe}^{3+}$ in the paint is reduced to $\mathrm{Fe}^{2+}$. The solubility and lack of color of $\mathrm{Fe}^{2+}$ means that it can be easily translocated from the IRIS tubes (Rabenhorst and Burch, 2006). 
The amount of paint removed is determined using a set of 5 IRIS tubes. The standard established for a soil to be considered hydric is a minimum of $30 \%$ iron paint removal within the top $30 \mathrm{~cm}$ for 3 of the 5 IRIS tubes (Rabenhorst and Burch, 2006).

\section{Hydrophytic Vegetation}

Wetland plant species are known as hydrophytic vegetation. They have evolved mechanisms to allow them to survive in saturated and anaerobic conditions. Wetland environments are dynamic due to the natural fluctuations of water levels and quality. Many hydrophytic plant species are able to tolerate both flooded conditions and periods of drought throughout the year. This unique adaptation is what distinguishes hydrophytic vegetation from other plant species (Brady and Weil, 2010).

Two broad categories of wetland vegetation include aquatic macrophytes and emergent macrophytes. Aquatic macrophytes are plants that live completely submerged, floating, or have a portion of the plant emerging from the water. Emergent macrophytes are wetland plants that are rooted in the soil and whose growth patterns result in the plants protruding above the water surface (Nahlik and Mitsch, 2006).

Typical adaptive features for wetland vegetation include hollow arenchyma tissue that transports oxygen from the leaves above water to the roots below the water surface. Certain trees such as the bald cypress produce "knees" or pneumatophores that are coneshaped extensions of the root system that extend from the ground. Knees function to obtain oxygen for the plant during flooded conditions and provide stability in the areas with shallow root systems due to high water table. Another adaptation, adventitious roots, is able to grow from the stem or leaf tissue rather than from another root in order to 
gain oxygen for the plant when typical roots would not have this ability (Tanaka et al., 2012).

Wetland vegetation indicator status denotes the probability of individual vegetation species to occur in a wetland or upland. The list of wetland plants and their respective indicator status is administered and updated by the U.S. Army Corps of Engineers (2008). Table 2-1 shows the indicator status and the description for that status. The indicator status of a plant is applied to the species as a whole; however, individual variations may exist within the species. The indicator status of vegetation plays a critical role in the vegetation parameter in wetland determinations (U.S. Army Corps of Engineers, 2008).

Table 2-1. Vegetation indicator categories for wetland delineation (U.S. Army Corps of Engineers, 2008).

\begin{tabular}{cc}
\hline Indicator Status & Description \\
\hline Obligate Wetland & Almost always occur in wetlands. \\
Facultative Wetland & Usually occur in wetlands, but may occur in non-wetlands. \\
Facultative & Occur in wetlands and non-wetlands. \\
Facultative Upland & Usually occur in non-wetlands, but may occur in wetlands. \\
Obligate Upland & Almost never occur in wetlands. \\
\hline
\end{tabular}

\section{Wetland Hydrology}

The duration and extent of saturation varies for different wetlands. The change in water table patterns is known as the hydroperiod and is also drastically different depending on the wetland location and type. For example, the hydroperiod of coastal marshes may be daily, while the hydroperiod of inland swamps; bogs or marshes are more seasonal (Brady and Weil, 2010). In addition, natural wetlands and mitigated or man-made wetlands vary in water-retention structure and duration. Water levels have 
been found to be higher and had less temporal variability in mitigated wetlands and in wetlands altered to include a retention structure than natural wetlands (Shaffer et al., 1999).

Wetland hydrology requires that the soil be both saturated and anaerobic for at least $14 \mathrm{~d}$ during the growing season (Craft et al., 2001). All wetlands are saturated for a period of time, but not all wetlands are saturated permanently. Problems arise if the soil is too cold for microbial or plant-root activity to occur. Oxygen may be dissolved in the water or trapped in the soil aggregates, as a result, anaerobic conditions may not develop (Brady and Weil, 2010). This situation would result in a non-wetland or oxyaquic classification.

Even in dry seasons, it is possible to observe evidence of wetland hydrology in the field. Such indicators include coating of sediment on plant detritus and water stains on trees and rocks. In addition, trees with above ground root masses indicate an adaptation to saturated conditions that can be observed during the dry season. Oncefloating branches and other debris create drift lines also suggest previous flooding (Brady and Weil, 2010). 


\section{Geology of California's Central Coast}

The central coast of California is located within the Coast Range Geomorphic Province of California and is an area characterized by a series of northwest trending mountains with intervening parallel river valleys. This topography is structurally controlled by strike-slip faulting with the boundaries of the valleys and ridges indicative of faults, which separate weak, erodible rocks from those resistant to erosion. Some of these faults are members of active San Andreas Fault System while others are older and delineate differing blocks of accreting rocks (Harden, 2004).

The Franciscan Assemblage is the dominant bedrock feature of the Coast Ranges. This feature was formed by several accreted oceanic blocks tectonically transported eastward and subducted beneath the North American Plate. The remaining sediments were accreted and uplifted onto the North American Plate. The sediments within the assemblage consist primarily of grey wacke sandstone, siltstone, shale, and mudstone. Less abundant and irregularly distributed are soft, greenish serpentine-rich sediments and ophiolitic blocks derived from blue schist blocks (Harden, 2004).

\section{Serpentinite}

\section{$\underline{\text { Serpentinitic Soils }}$}

Serpentinitic soils are formed from the weathering of ultramafic rocks formed from the basal or olivine-rich portion of an ophiolite sequence found in the oceanic crust along spreading centers. These rocks are generally Fe and $\mathrm{Mg}$ rich with very low silica content (Oze et al., 2008). 
The term ultramafic is colloquially known as "serpentine" rocks. Soils that form from ultramafic parent material reflect the geochemistry of the parent material. Peridotites and serpentines (metamorphosed peridotite) typically have high levels of $\mathrm{Mg}$, low $\mathrm{Ca}$ and $\mathrm{Al}$, with little to no $\mathrm{K}$. Heavy metals, including $\mathrm{Cr}$ and $\mathrm{Ni}$ are often found in moderate to high quantity in serpentine. Topographic position often plays a significant role in pedogenesis of serpentinitic terrain. In low-lying, poorly drained areas within the central California serpentinitic terrain, Mg-rich smectite (sapronite) is formed as a result of a high $\mathrm{pH}$ environment and an accumulation of $\mathrm{Mg}$ and silica by subsurface flow of water (Lee et al., 2004).

Soils that are categorized as serpentine Mollisols with aquic conditions have been commonly mapped with colluvium and alluvium materials of landslides, drainageways, and topographic depressions (Alexander et al., 2007). Such areas are quite limited in their extent and consequently, there is inadequate research about serpentine wetlands.

\section{Chemistry of Serpentinitic Soils}

Similar to the ultramafic parent material, serpentine soils have high concentrations of $\mathrm{Mg}$ and relatively low concentrations of $\mathrm{Ca}, \mathrm{K}$, and $\mathrm{P}$ making plant life less productive than in other soil ecosystems. As weathering occurs, $\mathrm{Mg}$ is leached and the concentration in the soil is diminished. Concentrations of $\mathrm{K}, \mathrm{P}$, and Ca increase with increased soil maturation. Aluminum, $\mathrm{Cr}$, and Fe are not leached from the soil, and as the soil matures, these elements become concentrated (Alexander et al., 2007). 


\section{Serpentine Geology}

Serpentinitic rock and soil comprise less than $1 \%$ of the earth's land surface and are found primarily along convergent plate margins throughout the Circum-Pacific and Mediterranean Regions of the earth (Alexander et al., 2007). Serpentinite is formed from the alteration or metamorphism of ultramafic rock or peridotite in the presence of water at temperatures less than $500^{\circ} \mathrm{C}$. This process is also called serpentinization where olivine and pyroxene are replaced by serpentine. Note that besides the serpentine minerals, which include chrysotile, lizardite, and antigorite; bructite and magnetite are also products of this metamorphism (Oze et al., 2008).

The large quantity of water required for the transformation results in large expansion and a decrease in density as the serpentine minerals take more space than those minerals they replace. During the serpentinization process, no changes in the relative amounts of various elements occur with the exception of the removal of $\mathrm{Ca}$. If carbon dioxide is available, the Ca will precipitate as carbonate. Serpentinization of ultramafic rock continues as the rocks are uplifted, faulted and fractured allowing migration of water into newly created openings (Alexander et al., 2007).

Serpentine soils are created from serpentinite and peridotite parent materials, which are mostly commonly found in mountainous terrain. These parent materials generally consist of disintegrated bedrock, which has been subject to erosion and masswasting forming deposits of colluvium with the thickest deposits located on footslopes. Soil formation is initiated by the weathering of peridotite and serpentine through exposure to air and water. Climate and the amount of available moisture play a large part in the depth of weathering. Once a veneer of soil covers the ground, the soil formation 
process is almost all chemically induced. Most all weathering involves acids with the primary source of acids being dissolved carbon dioxide in water, which forms a weak acid, carbonic acid. Serpentine is not stable in acidic environments which aids in the weathering process (Alexander et al., 2007).

\section{Conclusion}

Wetlands serve an important ecological and functional role in the environment. However, wetlands have been destroyed due to human practices and consequently, laws have been designed to protect remaining wetlands. For a region to be federally protected as a wetland, it must be delineated as such. The area must show wetland characteristics including hydric soils, vegetation, and hydrology. The benefits from wetlands are numerous including water purification, unique species, and flood prevention. Therefore, it is important to protect these areas from any further degradation by continuing scientific studies to improve understanding of wetlands (Brady and Weil, 2010). 


\section{CHAPTER 3 - HYDRIC SOIL EVALUATION USING IRIS TUBES}

\section{Introduction}

Wetlands are defined as areas that are saturated by surface and/or groundwater at a frequency and duration that anaerobic conditions occur and the species in the environment can only survive in such conditions (Brady and Weil, 2010). Wetlands are not only unique environments, but sensitive environments as well. Under Section 404 of the Clean Water Act, an area must be delineated a wetland in order to receive regulatory protection (U.S. Army Corps of Engineers, 2008). Delineation is based on a three-factor analysis, which includes the study of the hydrology, vegetation, and soil morphology of an area.

Hydric soils are formed in areas that are subject to flooding or inundation for a period of at least 14 days, which, in combination with microbial activity, results in oxygen depletion and anaerobic conditions. Organic matter accumulates while Fe and other reducible elements are reduced, translocated, or accumulated. Soil microbial activity is decreased in saturated conditions resulting in decreased decomposition and subsequent accumulation of organic matter. Microbial activity commonly reduces $\mathrm{Fe}^{3+}$ to $\mathrm{Fe}^{2+}$ causing bluish-gray to greenish-gray colors or gleys in the soil. Owing to its solubility, $\mathrm{Fe}^{2+}$ can be transported resulting in gray to reddish-gray colors, known as redox depletions, where Fe has been removed. These activities result in permanent characteristics in the soil that persevere through wet and dry periods (Brady and Weil, 2010).

Indicator of Reduction in Soil (IRIS) tubes are a tool utilized in the identification of hydric soils. Indicator of Reduction in Soils tubes are iron oxide coated, polyvinyl 
chloride (PVC) tubes. Under saturated conditions, soil microbes will oxidize organic matter utilizing the Fe oxyhydroxides on the tube as electron acceptors. This results in the paint being reduced and removed from the tube. A set of tubes (usually 5 or 6 ) is inserted into the soil to depths of $50 \mathrm{~cm}$ for a period of 2 weeks or more. Upon removal, the tubes are gently cleansed of soil and the amount of paint removed in the upper $30 \mathrm{~cm}$ is quantified (Rabenhorst, 2011).

The use of IRIS tubes is necessary in serpentine wetlands due to the lack of hydric soil research in these environments. Serpentine soils are generally deficient in plant essential nutrients such as $\mathrm{N}, \mathrm{K}, \mathrm{P}$, and $\mathrm{S}$. Although physical features of serpentine soils can vary considerably from site to site and within a site, serpentine soils are often found in open, steep landscapes with substrates that are generally shallow and rocky, often with a reduced capacity for moisture retention. Due to the intense selective pressure generated by such stressful edaphic conditions, serpentine soils promote speciation and the evolution of serpentine endemism. This contributes to unique biotas worldwide, including floras with high rates of endemism and species with disjunct distributions (Alexander et al., 2007).

Serpentine wetlands are unique and sensitive environments. Such areas are not only intrinsically valuable, but also serve a functional value through water purification and flood control. Due to the limited extent of these areas, there is inadequate research on the topic of serpentine wetlands and specifically serpentine hydric soils. It is vital to study these areas in order to protect them from further degredation. This study is important to contribute to the collection of hydric soil and serpentine data. 
The objective of this study was to determine (1) if the research sites are wetlands by evaluating the vegetation and hydrology and (2) to determine if the sites have hydric soils through the use of IRIS tubes and additional field research. 


\section{Materials and Methods}

Study Area

The study area is located in Poly Canyon in San Luis Obispo, California north of the California Polytechnic (Cal Poly) State University campus (Fig. 1-2). Two research sites (north and south) were established approximately $100 \mathrm{~m}$ from one another and were selected due to their similar hydrology, vegetation, and soil morphology.

\section{Field Procedures}

Morphological Description

One soil pit at each site was excavated to $1 \mathrm{~m}$ by hand at both the north and south research sites. Soil morphological descriptions were conducted with special attention given to redoximorphic features expression in the upper $50 \mathrm{~cm}$ of the profile (Schoeneberger, 2002). The results were compared to the field indicators specified in the Field Indicators of Hydric Soils in the United States (Vasilas et al., 2010). In order to document the adjacent upland soil, auger holes were excavated approximately $5 \mathrm{~m}$ upslope to a depth of approximately $0.5 \mathrm{~m}$.

\section{Preparation and Installation of IRIS Tubes}

The IRIS tubes were fabricated using the method described by Jenkinson (2003). Ferric chloride salt $\left(\mathrm{FeCl}_{3}\right)$ was dissolved in distilled water to produce iron oxide paint. Approximately $370 \mathrm{~mL}$ of $1 \mathrm{M} \mathrm{KOH}$ was added to obtain a $\mathrm{pH}$ of 12 and precipitate the iron oxide. The resulting solution was placed in dialysis tubing to remove the salts. The 
viscosity of the paint was adjusted by centrifution at $1000 \mathrm{rpm}$ for $5 \mathrm{~min}$. The paint was stored in an opaque glass container in a laboratory refrigerator.

Polyvinyl chloride (PVC) tubes were cut into approximately $60 \mathrm{~cm}$ lengths. Using acetone, the tubes were cleaned to remove any ink left by the manufacturers. To create a rough surface for the paint to adhere to, the tubes were sanded with very fine sand paper, approximately 220 grit. The iron oxide paint was applied to the lower $50 \mathrm{~cm}$ of the tube using a 2 in foam brush. To achieve an even coat, the tubes were spun using a power drill to simulate a lathe during the paint application.

Commencing on 15 January 2014, sets of 5 IRIS tubes were installed to a depth of $50 \mathrm{~cm}$ each week at both the north and south research sites. The IRIS tubes were installed using a 1.75 -inch diameter push probe to make a pilot hole so that the IRIS tube could be inserted into the soil with minimal abrasion yet ensuring soil contact. Tubes remained in place for 2 weeks and then were removed. Soil was gently cleansed from the tubes while in the field. A new set of tubes was installed in new holes immediately following tube removal.

Each tube was digitally photographed three times by rotating the tube $120^{\circ}$ around its circumference. Photos were cropped and merged in order to construct a single image of each tube surface. Using Adobe Photoshop, polygons were drawn around the areas of reduction and averaged for the set of 5 tubes in order to approximately calculate the total reduction occurring every 2 weeks at each research site (Castenson and Rabenhorst, 2006). 


\section{Volumetric Water Content}

The two research sites were instrumented with Decagon 5TM probes that were inserted into the soil at each site at approximately 10, 20,30, 40, and $50 \mathrm{~cm}$ of depth. The probes were connected to a data logger, which collected measurements of volumetric water content and temperature twice daily for the duration of the study.

\section{Vegetation Identification}

Vegetation was identified and categorized in accordance with the U.S. Army Corps of Engineers procedure for the arid west region (U.S. Army Corps of Engineers, 2008). The first step was to identify the wetland area using an aerial photograph or topographic map, or visually in the field. This is accomplished by determining the boundary where change in vegetation type occurs or a boundary where the soil changes from wet to dry. The vegetation were collected and pressed in the field for later species identification. Based on visual estimates, the absolute percent cover of plant species were made within the research area. Plants on the vegetative index are specifically listed as obligate, facultative wetland, facultative upland and facultative (Lichvar, 2012). The vegetation index and percent relative cover are included in the delineation of a wetland.

An area can be categorized as having hydrophytic vegetation by applying the dominance test (indicator 1) and/or prevalence index (PI) (indicator 2). The criteria for hydrophytic vegetation using the dominance test indicates that more than $50 \%$ of the dominant plant species are rated obligate, facultative wetland, or facultative. The prevalence index ranges from 1 to 5 . A prevalence index of 3.0 or less indicates that hydrophytic vegetation is present. To calculate the prevalence index, at least $80 \%$ of the 
total vegetation cover must be of species that have an assigned wetland indicator status or are upland species (U.S. Army Corps of Engineers, 2008).

\section{Laboratory Analyses}

Carbon Analysis

Soil samples were prepared and analyzed according the operating instructions from Elementar Analysensysteme GmbH for the use of the Vario MAX CNS Macro Elemental Analyzer (2005). The soil samples were air dried and passed through a $2 \mathrm{~mm}$ round-hole sieve. A $10 \mathrm{~g}$ sub-sample was obtained and ground to a fine powder using a mortar and pestle. Using an analytical balance, approximately $1000 \mathrm{mg}$ of the ground soil was placed into a clean, dry graphite crucible. The mass was recorded to the nearest tenth of a mg. The Vario MAX CNS Elementar Analyzer was used to determine total carbon and nitrogen in soil by combustion. 


\section{Results and Discussion}

Morphological Description

The studied soils are described as Fine, magnesic, active, thermic Typic Endoaquolls formed from colluvium and residuum weathered from serpentinite (Soil Survey Staff, 2010). This classification is consistent with the Obispo-Rock outcrop complex that is mapped in the area (Soil Survey Staff, 2012).

The research sites did not meet any of the Field Indicators of Hydric Soils. The soils at the research sites have very dark soil matrices consistent with high accumulation of organic matter. However, the carbon data (Fig. 3-5) shows that the dark color is not a result of organic matter. Rather, the dark color is likely caused by the weathering of the serpentinite parent material and, therefore, does not meet a Field Indicators of Hydric Soils. The south research site had no redox concentrations (Table 3-1a). The north research site did have redox concentrations present, but the abundance and coloring did not meet the indicator necessary for the soil to be delineated as hydric (Table 3-1b) (U.S. Army Corps of Engineers, 2008). 
Table 3-1a. Description of soil at south research site (all colors were recorded moist unless otherwise noted).

\begin{tabular}{ccl}
\hline Horizon & Depth (cm) & \multicolumn{1}{c}{ Description } \\
\hline $\mathrm{A}$ & $1-7$ & $\begin{array}{l}\text { Black (N 2.5/0) clay loam; many fine roots, clear smooth boundary. } \\
\text { Bulk density is } 1.56 \mathrm{~g} / \mathrm{cm}^{3} .\end{array}$ \\
$\mathrm{Bg} 1$ & $7-28$ & $\begin{array}{l}\text { Black (N 2.5/0) clay loam; weak medium to coarse subangular } \\
\text { blocky structure; common medium roots; abrupt smooth boundary. } \\
\text { Bulk density is } 1.62 \mathrm{~g} / \mathrm{cm}^{3} .\end{array}$ \\
$\mathrm{Bg} 2$ & $28-50$ & $\begin{array}{l}\text { Black }(\mathrm{N} 2.5 / 0) \text { clay; weak medium to coarse subangular blocky } \\
\text { structure; few medium to fine roots; gradual smooth boundary. Bulk } \\
\text { density is } 1.51 \mathrm{~g} / \mathrm{cm}^{3} .\end{array}$ \\
$\mathrm{Bg} 3$ & $\begin{array}{l}\text { Black }(\mathrm{N} 2.5 / 0) \text { clay; weak medium to coarse subangular blocky } \\
\text { structure; friable. }\end{array}$ \\
\hline
\end{tabular}

Table 3-1b. Description of soil at north research site (all colors were recorded moist unless otherwise noted).

\begin{tabular}{|c|c|c|}
\hline Horizon & Depth (cm) & Description \\
\hline A1 & $0-13$ & $\begin{array}{l}\text { Very dark brown (10YR 2/2) sandy loam with common (4\%) color } \\
\text { (10YR 3/4) distinct concentrations of iron; weak medium subangular } \\
\text { blocky structure; many fine, common coarse, and many medium } \\
\text { roots; abrupt smooth boundary. Bulk density is } 1.69 \mathrm{~g} / \mathrm{cm}^{3} \text {. }\end{array}$ \\
\hline A2 & $13-30$ & $\begin{array}{l}\text { Black (N 2.5/0) clay loam with common }(15 \%) \text { prominent dark } \\
\text { grayish green }(5 \mathrm{G} 3.5 / 1) \text { depletions and few }(1 \%) \text { prominent } \\
\text { yellowish brown }(10 \mathrm{YR} 5 / 8) \text { concentrations of iron; weak medium } \\
\text { subangular blocky structure; many medium, common coarse, and } \\
\text { common fine roots; clear smooth boundary. Bulk density is } 1.59 \\
\mathrm{~g} / \mathrm{cm}^{3} \text {. }\end{array}$ \\
\hline $\mathrm{AB}$ & $30-53$ & $\begin{array}{l}\text { Black (N } 2.5 / 0) \text { clay loam with common }(7 \%) \text { distinct dark grayish } \\
\text { green }(5 \mathrm{G} 3.5 / 1) \text { and few ( } 1 \% \text { ) prominent yellowish brown ( } 10 \mathrm{YR} \\
5 / 8 \text { ) concentrations of iron; weak medium subangular blocky } \\
\text { structure; common medium, fine common, and few fine roots; } \\
\text { abrupt smooth boundary. Bulk density is } 1.66 \mathrm{~g} / \mathrm{cm}^{3} \text {. }\end{array}$ \\
\hline $\mathrm{Bg} 1$ & $53-72$ & $\begin{array}{l}\text { Dark greenish gray (5BG 3/1) clay loam; weak medium subangular } \\
\text { blocky structure; common medium and few fine roots; clear smooth } \\
\text { boundary. Bulk density is } 1.49 \mathrm{~g} / \mathrm{cm}^{3} \text {. }\end{array}$ \\
\hline Bg2 & $72-88$ & $\begin{array}{l}\text { Dark greenish gray ( } 5 \mathrm{BG} 3 / 1) \text { clay; massive structure; few fine } \\
\text { roots; clear smooth boundary. Bulk density is } 1.67 \mathrm{~g} / \mathrm{cm}^{3} \text {. }\end{array}$ \\
\hline Bg3 & $88+$ & $\begin{array}{l}\text { Dark greenish gray ( } 5 \mathrm{GY} 3 / 1) \text { clay; common (10\%) distinct ( } 5 \mathrm{G} 4 / 2) \\
\text { depletions. }\end{array}$ \\
\hline
\end{tabular}


Indicator of Reduction in Soil (IRIS) Tubes

The study began during a dry period in January when the soil was dry and oxidized. Both research sites followed a pattern of oxidized soil conditions at the beginning of the study and reduced soil conditions after sufficient water from rain events later in the study. The south research site had approximately $30 \%$ paint removal in the top $15 \mathrm{~cm}$ and increased to over $80 \%$ at the end of the study (Fig. 3-2a). The north research site had approximately $10 \%$ paint removal in the top $15 \mathrm{~cm}$ and increased to over $50 \%$ at the end of the study (Fig. 3-2b). Therefore, both research sites exceed the technical standard for paint removal for hydric soils and through the use of IRIS tubes have proven that the soil was saturated long enough to produce reduced conditions. 


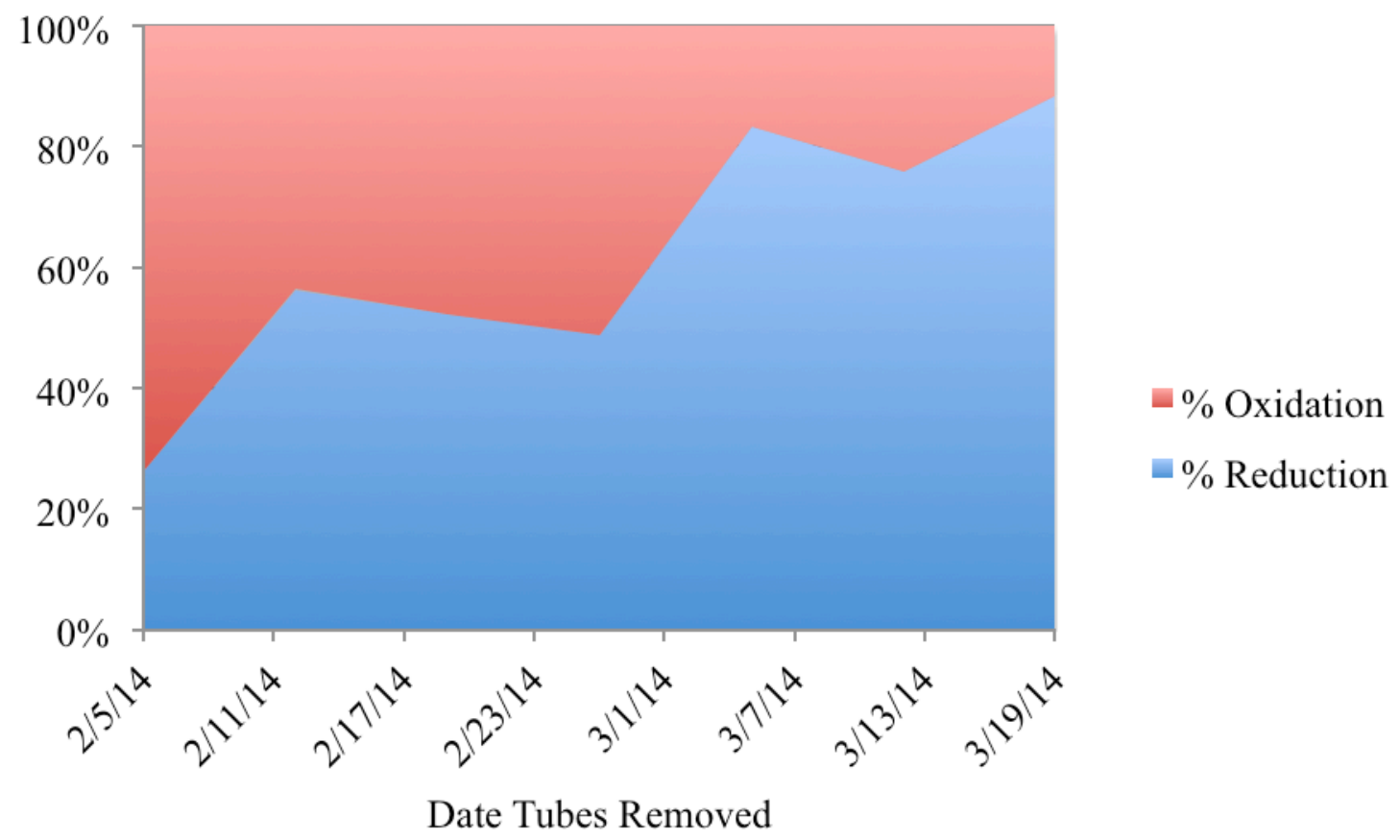

Figure 3-1a. Average percentage of oxidation and reduction (iron oxide paint removal) from the top $15 \mathrm{~cm}$ section of the tubes using Indicator of Reduction in Soil (IRIS) tubes removed in February and March 2014 at the south research site.

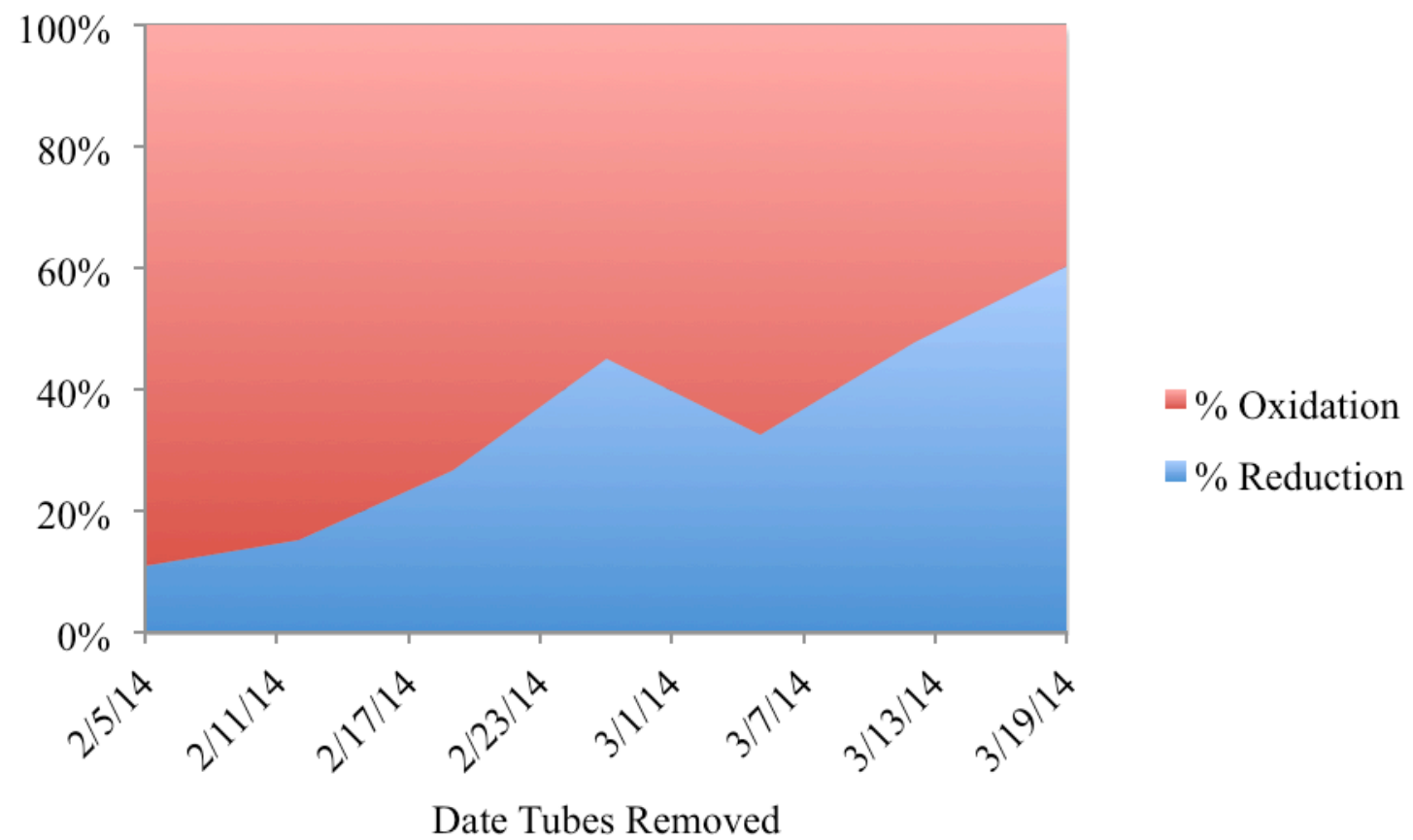

Figure 3-1b. Average percentage of oxidation and reduction (iron oxide paint removal) from the top $15 \mathrm{~cm}$ section of the tubes using Indicator of Reduction in Soil (IRIS) tubes removed in February and March 2014 at the north research site. 


\section{Hydrology}

The research sites had visual indicators including ponding on the soil surface present throughout the length of the study. In order to gain a more quantitative hydrology data, volumetric water content was measured. The volumetric water content, or volume wetness, is defined as the percent of water relative to a sample volume of soil (Brady and Weil, 2010). The volumetric water content is used as a proxy to determine saturation at the sites. To determine saturation, porosity was calculated using bulk density (Table 32a, Table 3-2b). The average porosity for the south research site was $41 \%$ and $39 \%$ for the north research site. Therefore, it is expected that a volumetric water content value of approximately $40 \%$ or greater indicates a saturated soil.

The study began during a drier period in January where volumetric water content was low, approximately $42 \%$, in the top portion of the soil profile, but still saturated (Fig. 3.3). Water was retained throughout the drier weeks throughout the soil profile as a result of high clay content. Volumetric water content was expected to increase following rain events in February. Both research sites followed this pattern of rapid increase in volumetric water content following rain events and consistent saturation throughout the length of the study. Volumetric water content measured at the sites indicates the sites have wetland hydrology. 


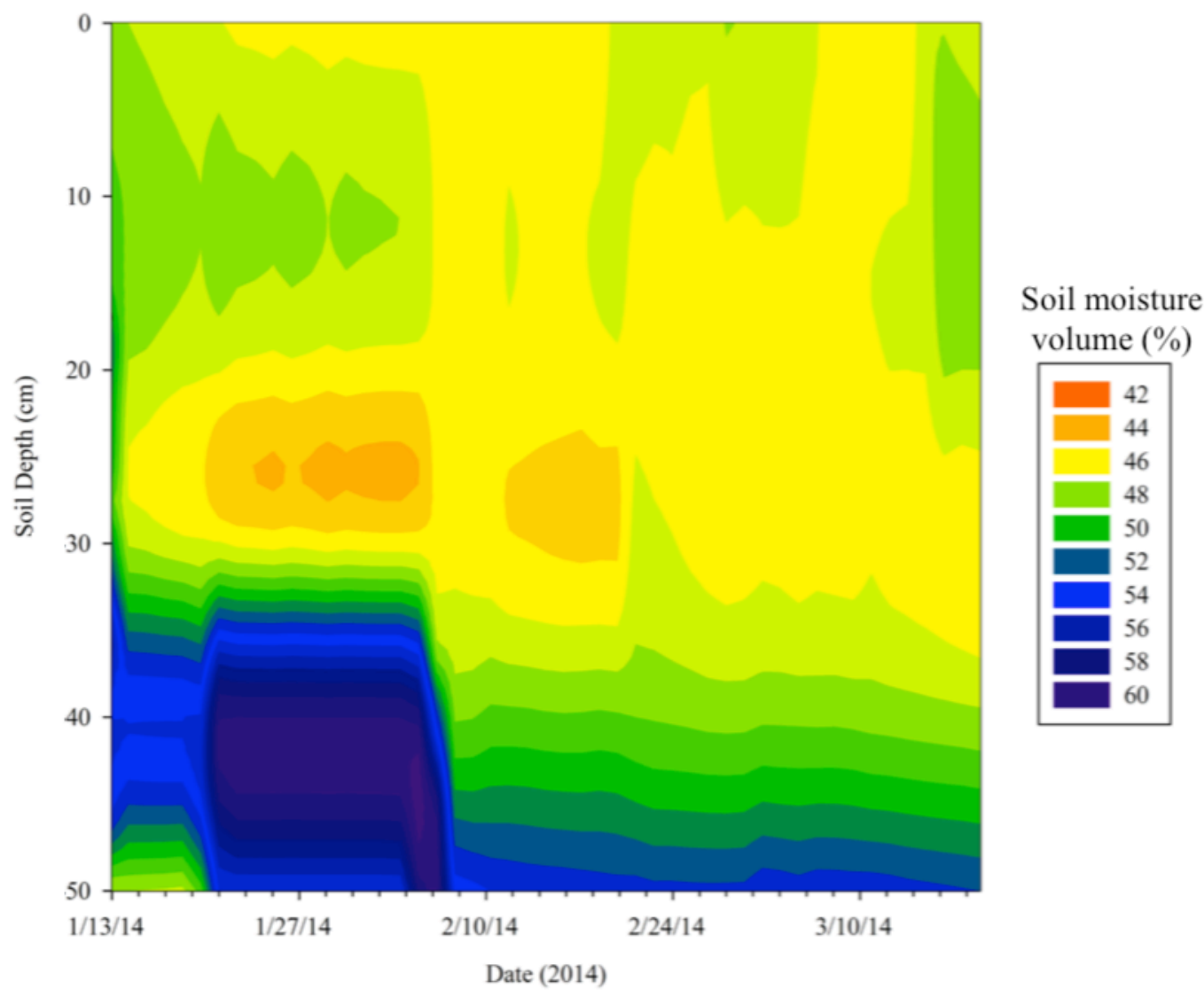

Figure 3-2a. Soil volumetric water content measured at 10, 20, 30, 40, and $50 \mathrm{~cm}$ below the soil surface from January to March 2014 at the south research site. 


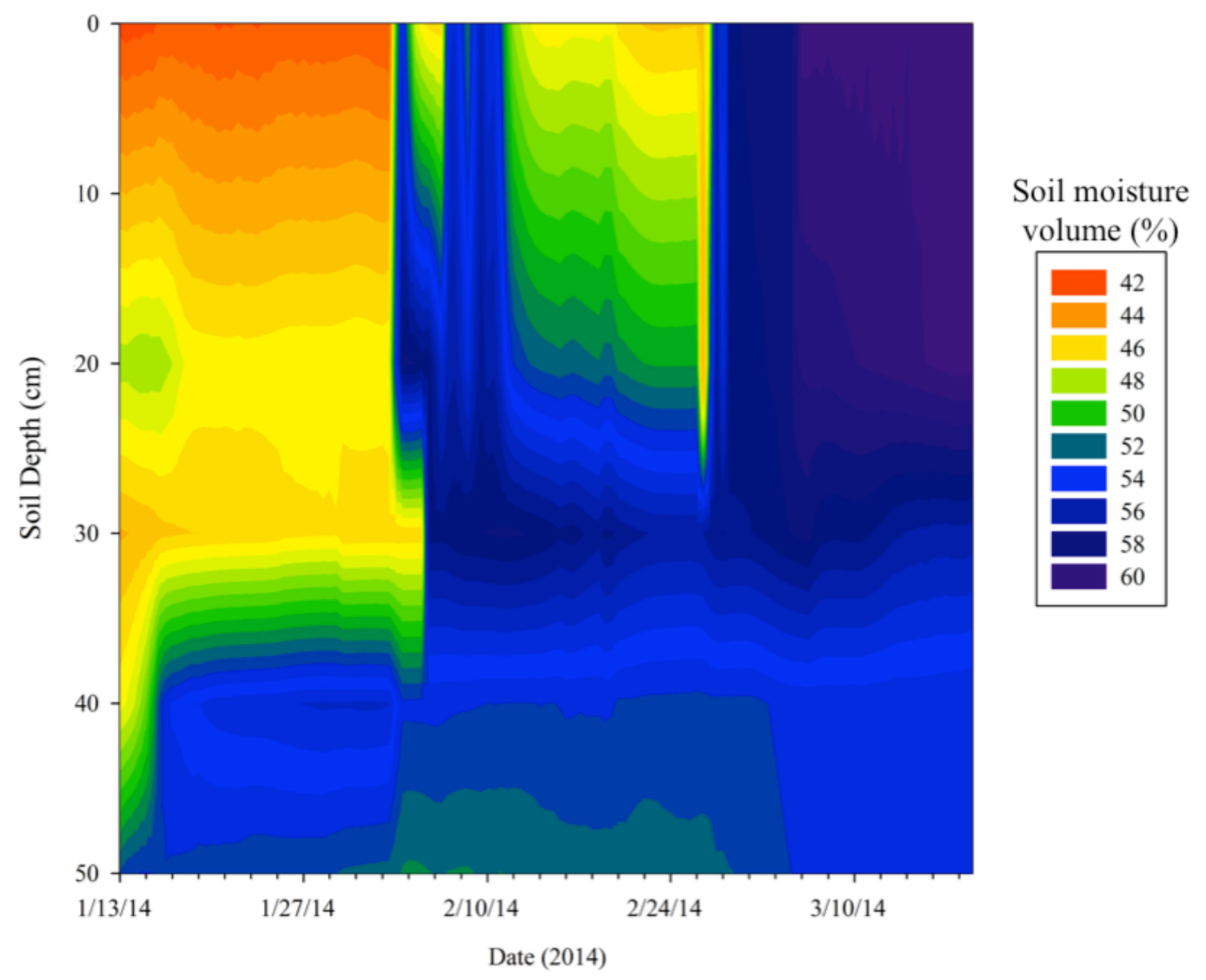

Figure 3-2b. Soil volumetric water content measured at 10, 20, 30, 40, and $50 \mathrm{~cm}$ below the soil surface from January to March 2014 at the north research site. 


\section{$\underline{\text { Vegetation }}$}

The prevalence index is required to be 3 or less to be considered hydrophytic (U.S. Army Corps of Engineers, 2008). Table 3-2a and Table 3-2b show indicator status and absolute percent cover of the species present in the south and north research sites. The vegetation at the south research site had a prevalence index of 1.6 and the north research site had a prevalence index of 2.9. Based on the field analysis, the vegetation at the research sites is hydrophytic. 
Table 3-2a. Vegetation analysis using the prevalence index for the south research site.

\begin{tabular}{|c|c|c|c|c|c|}
\hline Indicator Status & Species Name & $\begin{array}{l}\text { Absolute } \\
\text { \% Cover }\end{array}$ & $\begin{array}{c}\text { Total Cover } \\
\text { by Group }\end{array}$ & Multiply by ${ }^{\dagger}$ & Product \\
\hline \multirow[t]{3}{*}{ OBL species } & Juncus phaecocephalus & 30 & & & \\
\hline & Mimulus guttatus & 1 & & & \\
\hline & Solidago confinis & 5 & 36 & 1 & 36 \\
\hline \multirow[t]{3}{*}{ FAC-W species } & Carex serratodens & 5 & & & \\
\hline & Juncus balticus & 25 & & & \\
\hline & Stachys pycnantha & 8 & 38 & 2 & 76 \\
\hline FAC species & none & 0 & 0 & 3 & 0 \\
\hline \multirow[t]{2}{*}{ FAC-U species } & Cynodon dactylon & 2 & & & \\
\hline & Ranunculus californicus & 1 & 3 & 4 & 12 \\
\hline UPL species & none & 0 & 0 & 5 & 0 \\
\hline Sum & & & $77(\mathrm{~A})$ & & $124(\mathrm{~B})$ \\
\hline $\begin{array}{l}\text { Hydrophytic } \\
\text { Vegetation } \\
\text { Determination }\end{array}$ & & & \multicolumn{3}{|c|}{$\begin{array}{l}\text { Prevalence index }=\mathrm{B} / \mathrm{A}=124 / 77 \text {; therefore, this } \\
\text { community is hydrophytic by indicator } 1.6 \\
\text { (prevalence index). }\end{array}$} \\
\hline
\end{tabular}

${ }^{\dagger}$ Where $\mathrm{OBL}=1, \mathrm{FAC}-\mathrm{W}=2, \mathrm{FAC}=3, \mathrm{FAC}-\mathrm{U}=4$, and $\mathrm{UPL}=5$

Table 3-2b. Vegetation analysis using the prevalence index for the north research site.

\begin{tabular}{|c|c|c|c|c|c|}
\hline Indicator Status & Species Name & $\begin{array}{l}\text { Absolute } \\
\text { \% Cover }\end{array}$ & $\begin{array}{c}\text { Total Cover } \\
\text { by Group }\end{array}$ & Multiply by ${ }^{\dagger}$ & Product \\
\hline OBL species & Mimulus guttatus & 4 & & & \\
\hline & Solidago confinis & 2 & 6 & 1 & 6 \\
\hline FAC-W species & Carex serratodens & 6 & & & \\
\hline & Juncus balticus & 9 & & & \\
\hline & Juncus phaecocephalus & 21 & 26 & 2 & 52 \\
\hline FAC species & none & 0 & 0 & 3 & 0 \\
\hline FAC-U species & Cynodon dactylon & 34 & & & \\
\hline & Ranunculus californicus & 1 & 35 & 4 & 140 \\
\hline UPL species & none & 0 & 0 & 5 & 0 \\
\hline Sum & & & $67(\mathrm{~A})$ & & $198(\mathrm{~B})$ \\
\hline $\begin{array}{l}\text { Hydrophytic } \\
\text { Vegetation } \\
\text { Determination }\end{array}$ & & & \multicolumn{3}{|c|}{$\begin{array}{l}\text { Prevalence index }=\mathrm{B} / \mathrm{A}=124 / 77 \text {; therefore, this } \\
\text { community is hydrophytic by indicator } 2.9 \\
\text { (prevalence index). }\end{array}$} \\
\hline
\end{tabular}




\section{Carbon Content}

It is assumed that carbon content will be greatest in the top portion of the soil profile, defined as the upper $30 \mathrm{~cm}$, and decrease with depth. Both research sites displayed this assumed pattern, which is likely due to their similar aspects and cover vegetation (Fig. 3.5). The soils of the north research site showed a steady decrease in carbon content through the soil profile. In contrast, the carbon content of the soils at the south research site had an increase of approximately $1 \%$ at 30 to $50 \mathrm{~cm}$ of depth and then decreased in carbon to the bottom of the soil profile. The soil north research site had a substantially greater $\mathrm{C}$ content than the south research site. The soils of the north and south research sites generally contained a sufficient amount of organic carbon in the upper part to sustain microbial activity (Fig. 3-5). 


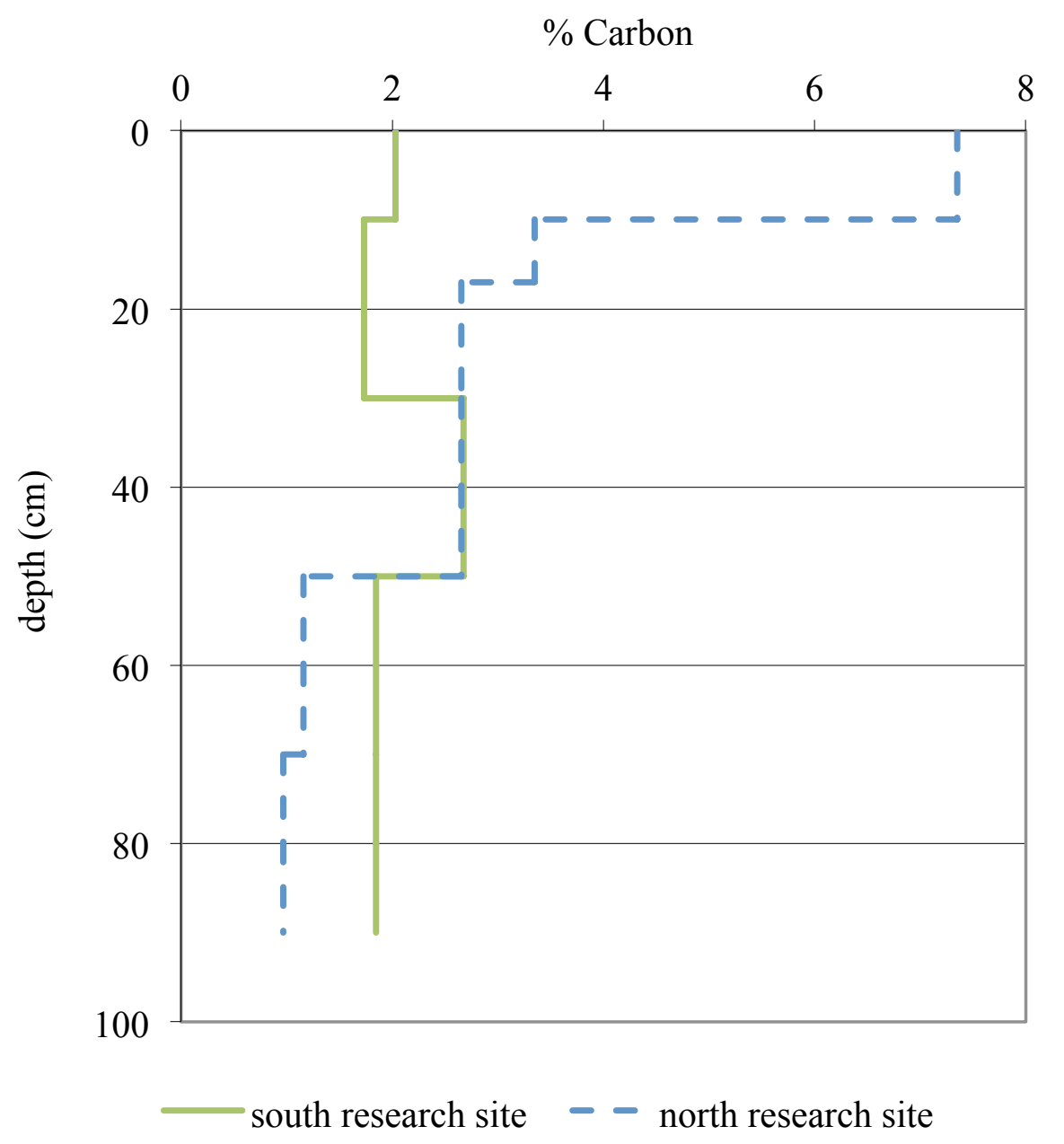

Figure 3-3. Total carbon percentage for soils at the north and south research sites. 


\section{Conclusions}

The north and south research sites meet two of the three criteria necessary for wetland determination. Two primary indicators of wetland hydrology were observed; saturated soil conditions and surface ponding. Additionally, the research sites meet the standards for hydrophytic vegetation with a prevalence index (PI) of less than 3.0; PI was 1.6 at the south research site and 2.9 at the north research site (U.S. Army Corps of Engineers, 2008). However, these soils do not meet a currently approved Field Indicator of Hydric Soils.

The results of the IRIS tube analyses indicate that the soils at both research sites are reduced with respect to iron, and therefore anaerobic for greater than 14 days during the growing season. Therefore, the soils at the north and south research sites are hydric.

This year was the third driest year on record for San Luis Obispo County. The research sites met wetland criteria despite this drought. It can be expected that these sites would meet wetland criteria if further research were conducted during an average year of rainfall. 


\section{CHAPTER 4 - MORPHOLOGY OF SERPENTINITIC HYDRIC SOILS}

\section{Introduction}

The identification of hydric soils, hydrophytic vegetation, and wetland hydrology are the three factors necessary for the delineation of wetlands (Army Corps of Engineers, 2008). The delineation of wetlands is an important aspect of land use planning and resource development (Berkowitz and Sallee, 2011). In order to identify hydric soils, Field Indicators of Hydric Soils were developed (Vasilas et al., 2010). These indicators typically focus on the morphologic features that result from prolonged and repeated anaerobic soil conditions in upper portions of a soil profile (Mausbach, 1994). Indications of hydric soils include organic matter accumulation, redoximorphic concentrations, and development of low-chroma colors through the reduction and translocation of solid-phase Fe and Mn species (Vepraskas, 1992).

The National Technical Committee for Hydric Soils (NTCHS) is responsible for the development of Field Indicators of Hydric Soils and determination of relevance to differing geographical regions (Vasilas et al., 2010). A Hydric Soil Technical Standard (HSTS) was established by the NTCHS to assess the hydric status of a soil. In addition, the HSTS is responsible for the modification or adoption of new field indicators, as well soils believed to meet the hydric soil definition but do not meet approved field indicator morphology (Berkowitz and Sallee, 2011).

Soils that do not have developed characteristics commonly used for delineation and do not meet approved Field Indicators of Hydric Soils, but are still considered hydric are known as problematic hydric soils (Berkowitz and Sallee, 2011). Problematic hydric soil morphology may develop as a result of several factors including high alkalinity, which 
limits the dissolution and translocation of solid-phase Fe and Mn species, low organic matter content, which restricts microbial activity and reduces electron sources, low Fe content, which results in decreased alternate electronic acceptors, and parent materials, such as serpentinite, that are dark in color and can conceal redoximorphic features (U.S. Army Corps of Engineers, 2008).

Serpentine soils are formed from weathering of ultramafic rocks. The distinctive chemistry of ultramafic rocks creates unique soil color and chemistry and restricts vegetative growth. Serpentine soils are not only unique, but also limited in extent (Alexander et al., 2007). Consequently, the research on serpentine wetlands and hydric soils is minimal and there is a clear need for additional field and laboratory studies.

As discussed in Chapter 3, the research sites did not meet an approved Field Indicators of Hydric Soils but met the qualifications for wetland hydrology and vegetation. The use of IRIS tubes indicated the research sites contained hydric soils. Therefore, the objective of this study was to develop criteria necessary for a new test Field Indicator of Hydric Soils for use in soils formed in serpentinitic parent materials along the Central Coast of California. 


\section{Materials and Methods}

Study Area

The study area is located in Poly Canyon in San Luis Obispo, California north of California Polytechnic State University’s campus (Fig. 1-2). Two research sites (north and south) were established approximately $100 \mathrm{~m}$ from one another and were selected due to their similar parent material, hydrology, geomorphology, and soil morphology.

\section{Field Procedures}

Morphological Description and Bulk Density Clod Collection

In order to minimize disturbance, soil pits were excavated by hand at both the north and south research sites. Soil morphological descriptions were conducted with special attention given to redoximorphic features expression in the upper $50 \mathrm{~cm}$ of the profile (Schoeneberger, 2002). The results were compared to the field indicators specified in the Field Indicators of Hydric Soils in the U.S. (Vasilas et al., 2010). In order to document the adjacent upland soil, auger holes were excavated to approximately $5 \mathrm{~m}$ upslope at both sites.

While in the field, a total of eight soil clods were collected from increasing depths; three from the south research site and five from the north research site. The soil clods were wrapped in a hair net, coated in saran resin, and hung to dry in the field. Bulk density was determined in accordance with the procedure published by Blake and Hartge (1986). 


\section{Laboratory Analyses}

\section{Bulk Density}

The clods collected in the field were carefully transported to the laboratory for further experimentation (Blake and Hartge, 1986). In the laboratory, a 4-Lbeaker filled with approximately 2 -L of water were placed on a top-loading balance scale and the weight adjusted with water to a known amount. To determine the clod volume, the clods were suspended and completely immersed in the water and the weight recorded. The weight difference before and after adding the clod was calculated, with the weight difference equaling the clod volume. The moisture content of each clod was determined by breaking open clods and taking a sub-sample of soil. The weight of the sample was recorded, and the sample oven-dried and the weight of the oven-dried sample recorded. The equation for soil moisture content is:

$$
M=\frac{W w-W d}{W w} \times 100 \%
$$

where $\mathrm{M}$ is the percent moisture content; $\mathrm{Ww}$, wet weight of the sample (g); and $\mathrm{Wd}$, weight of the sample after drying $(\mathrm{g})$.

\section{Carbon Analysis}

Soil samples were prepared and analyzed according the operating instructions from Elementar Analysensysteme GmbH for the use of the Vario MAX CNS Macro Elemental Analyzer (2005). The soil samples were air dried and passed through a $2 \mathrm{~mm}$ round-hole sieve. A $10 \mathrm{~g}$ sub-sample was obtained and ground to a fine powder using a mortar and pestle. Using an analytical balance, approximately $1000 \mathrm{mg}$ of the ground soil was placed into a clean, dry graphite crucible. The mass was recorded to the nearest 
tenth of a milligram. A Vario MAX CNS Elementar Analyzer was used to determine total carbon and nitrogen in soil by combustion.

\section{Particle Size Analysis}

A total of nine soil samples were collected; four from the south research site and five from the north research site. The Bouyoucos method was employed to determine laboratory textures for each soil sample (Bouyoucos, 1962). A $1000 \mathrm{ml}$ cylinder of deionized water was utilized as a blank. Approximately $50 \mathrm{~g}$ of air-dried soil and $100 \mathrm{ml}$ of a $5 \%$ solution of sodium hexametaphosphate and deionized water were placed in a mechanical dispersing mixer and mixed for 1 minute. The suspension was transferred to a $1000 \mathrm{ml}$ cylinder and deionized water added to fill to $1000 \mathrm{ml}$ mark. The cylinder was then capped and turned end over end for one minute. Hydrometer and temperature readings of the suspension and blank were recorded at 40 seconds and 2 hours elapsed time. Hydrometer readings were corrected by adding 0.36 gram/liter for every 1 degree above $20 \mathrm{C}$ or subtracting 0.36 gram/liter for every 1 degree below $20 \mathrm{C}$. 


\section{Results and Discussion}

Morphological Description

The soils at the research sites are classified as Fine, magnesic, active, thermic Typic Endoaquolls and the upland soils are Fine, magnesic, active, thermic, Typic Haploxerolls (Soil Survey Staff, 2010). The parent material of the soils from both the research sites and the upland sites are colluvium and residuum weathered from serpentinite. The south research site had no redox concentrations (Table 4-1a). The north research site did have redox concentrations present, but the abundance and coloring did not meet the indicator necessary for the soil to be delineated as hydric (Table 4-1b) (U.S. Army Corps of Engineers, 2008). Although the research sites had very dark soil matrices consistent with organic matter accumulation, the carbon data (Fig. 4-3) shows that the dark color is not likely a result of organic matter. Rather, the dark color is likely caused by the weathering of the serpentinite parent material and, therefore, does not meet a hydric soil field indicator.

The soils of the Upland Sites had no evidence of wetness including an absence of redox concentration and depletions and did not meet the Field Indicators of Hydric Soils (Appendix C). 
Table 4-1a. Description of soil at south research site (all colors were recorded moist unless otherwise noted).

\begin{tabular}{ccl}
\hline Horizon & Depth (cm) & \multicolumn{1}{c}{ Description } \\
\hline $\mathrm{A}$ & $1-7$ & $\begin{array}{l}\text { Black (N 2.5/0) clay loam; many fine roots, clear smooth boundary. } \\
\text { Bulk density is } 1.56 \mathrm{~g} / \mathrm{cm}^{3} .\end{array}$ \\
$\mathrm{Bg} 1$ & $7-28$ & $\begin{array}{l}\text { Black (N 2.5/0) clay loam; weak medium to coarse subangular } \\
\text { blocky structure; common medium roots; abrupt smooth boundary. } \\
\text { Bulk density is } 1.62 \mathrm{~g} / \mathrm{cm}^{3} .\end{array}$ \\
$\mathrm{Bg} 2$ & $28-50$ & $\begin{array}{l}\text { Black }(\mathrm{N} 2.5 / 0) \text { clay; weak medium to coarse subangular blocky } \\
\text { structure; few medium to fine roots; gradual smooth boundary. Bulk } \\
\text { density is } 1.51 \mathrm{~g} / \mathrm{cm}^{3} .\end{array}$ \\
$\mathrm{Bg} 3$ & $\begin{array}{l}\text { Black }(\mathrm{N} 2.5 / 0) \text { clay; weak medium to coarse subangular blocky } \\
\text { structure; friable. }\end{array}$ \\
\hline
\end{tabular}

Table 4-1b. Description of soil at north research site (all colors were recorded moist unless otherwise noted).

\begin{tabular}{|c|c|c|}
\hline Horizon & Depth (cm) & Description \\
\hline A1 & $0-13$ & $\begin{array}{l}\text { Very dark brown (10YR 2/2) sandy loam with common (4\%) color } \\
\text { (10YR 3/4) distinct concentrations of iron; weak medium subangular } \\
\text { blocky structure; many fine, common coarse, and many medium } \\
\text { roots; abrupt smooth boundary. Bulk density is } 1.69 \mathrm{~g} / \mathrm{cm}^{3} \text {. }\end{array}$ \\
\hline A2 & $13-30$ & $\begin{array}{l}\text { Black (N 2.5/0) clay loam with common }(15 \%) \text { prominent dark } \\
\text { grayish green }(5 \mathrm{G} 3.5 / 1) \text { depletions and few }(1 \%) \text { prominent } \\
\text { yellowish brown }(10 \mathrm{YR} 5 / 8) \text { concentrations of iron; weak medium } \\
\text { subangular blocky structure; many medium, common coarse, and } \\
\text { common fine roots; clear smooth boundary. Bulk density is } 1.59 \\
\mathrm{~g} / \mathrm{cm}^{3} \text {. }\end{array}$ \\
\hline $\mathrm{AB}$ & $30-53$ & $\begin{array}{l}\text { Black (N } 2.5 / 0) \text { clay loam with common }(7 \%) \text { distinct dark grayish } \\
\text { green }(5 \mathrm{G} 3.5 / 1) \text { and few ( } 1 \% \text { ) prominent yellowish brown ( } 10 \mathrm{YR} \\
5 / 8 \text { ) concentrations of iron; weak medium subangular blocky } \\
\text { structure; common medium, fine common, and few fine roots; } \\
\text { abrupt smooth boundary. Bulk density is } 1.66 \mathrm{~g} / \mathrm{cm}^{3} \text {. }\end{array}$ \\
\hline $\mathrm{Bg} 1$ & $53-72$ & $\begin{array}{l}\text { Dark greenish gray (5BG 3/1) clay loam; weak medium subangular } \\
\text { blocky structure; common medium and few fine roots; clear smooth } \\
\text { boundary. Bulk density is } 1.49 \mathrm{~g} / \mathrm{cm}^{3} \text {. }\end{array}$ \\
\hline Bg2 & $72-88$ & $\begin{array}{l}\text { Dark greenish gray ( } 5 \mathrm{BG} 3 / 1 \text { ) clay; massive structure; few fine } \\
\text { roots; clear smooth boundary. Bulk density is } 1.67 \mathrm{~g} / \mathrm{cm}^{3} \text {. }\end{array}$ \\
\hline Bg3 & $88+$ & $\begin{array}{l}\text { Dark greenish gray ( } 5 \mathrm{GY} 3 / 1) \text { clay; common (10\%) distinct ( } 5 \mathrm{G} 4 / 2) \\
\text { depletions. }\end{array}$ \\
\hline
\end{tabular}




\section{Particle Size Distribution}

The research sites are on very gentle slopes $(2 \%)$ resulting in low runoff rates with the majority of water moving over the soil surface infiltrating into the system. Therefore, it is important to focus on the physical features of the soil to understand how water moves within the soil system. Textural class and clay percentage are used to interpret the ability of a soil to hold water as well as the ability of water to move through the soil profile. Water translocates clay so with an understanding of water movement, it is possible to understand deposition and subsequent accumulation of clay.

At both research sites, the textural classes are primarily clay loams and clays, with a high percentage of clay (Table 4-1 and full particle size distribution data available in Appendix A). High percentage of clay indicates the profiles have a strong ability to hold water longer after rain events. In the south research site, clay gradually increases throughout the soil profile indicating that the water source is most likely from runoff and precipitation (Fig. 3-4). In the north research site, the clay gradually increases to $38 \%$ until approximately $50 \mathrm{~cm}$ then decreases to $32 \%$ clay until $70 \mathrm{~cm}$ where it begins to gradually increase again (Fig. 3-4). This indicates that water enters the soil system both from above, rainfall, and below, from groundwater. 


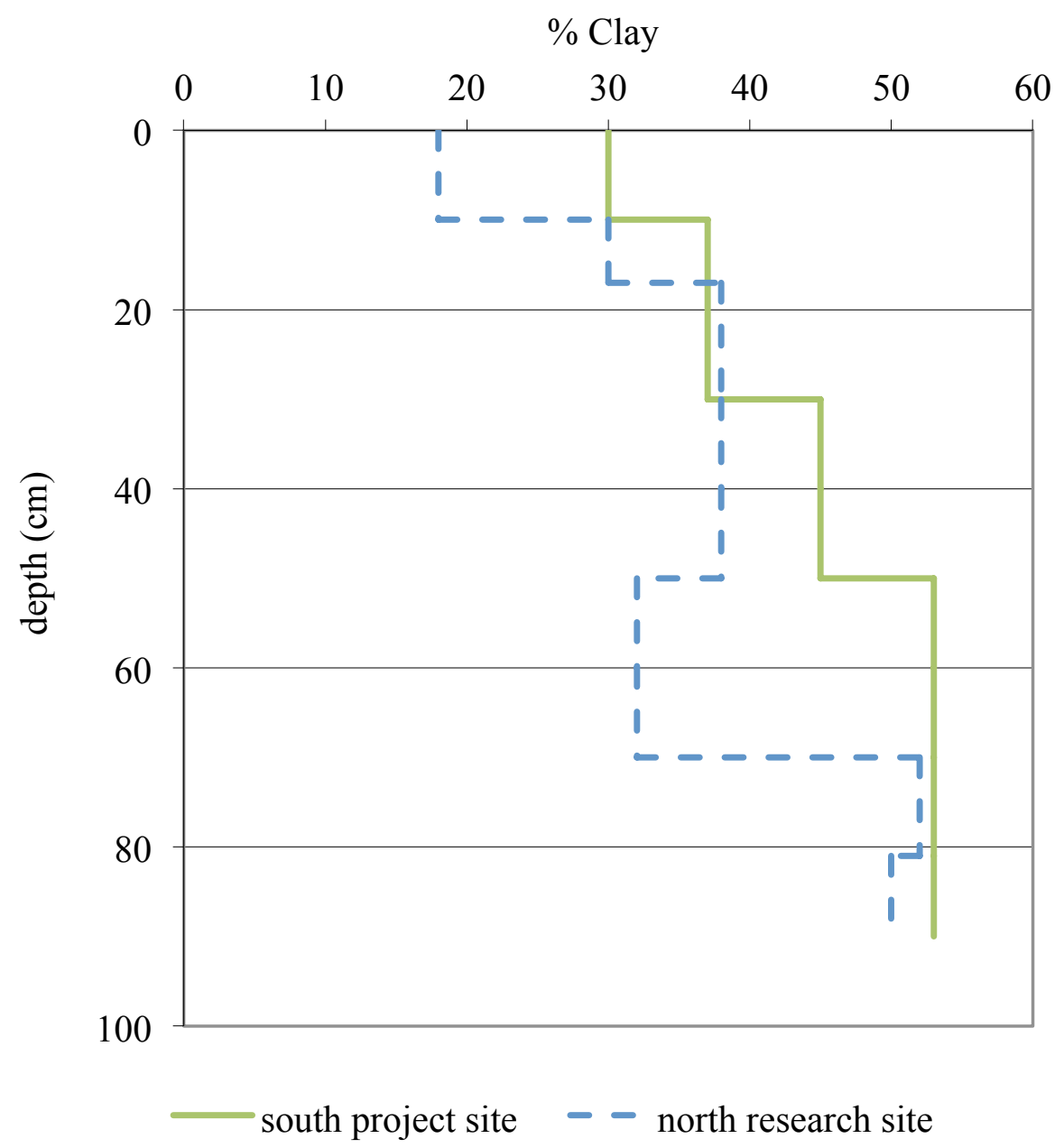

Figure 4-1. Total clay percentage for soils at the north and south research sites. 


\section{Carbon Content}

The soil at the research sites displayed similar patterns of carbon being greatest near the soil surface, defined as $30 \mathrm{~cm}$, and decreasing with depth through the soil profile (Fig. 3-5). However, The south research site had approximately 5\% less carbon in the top horizon than the north research sites. The carbon levels at 40 and $60 \mathrm{~cm}$ were much lower than those in the top portion of the profile. At approximately $60 \mathrm{~cm}$, the carbon contents of both research sites reached a similar level and steadily decreased to the bottom of the soil profile. The soils of the north and south research sites generally contained a sufficient amount of organic carbon in the upper part to sustain microbial activity; therefore, carbon does not appear to be a limiting factor for reduction (Fig. 4-2). 


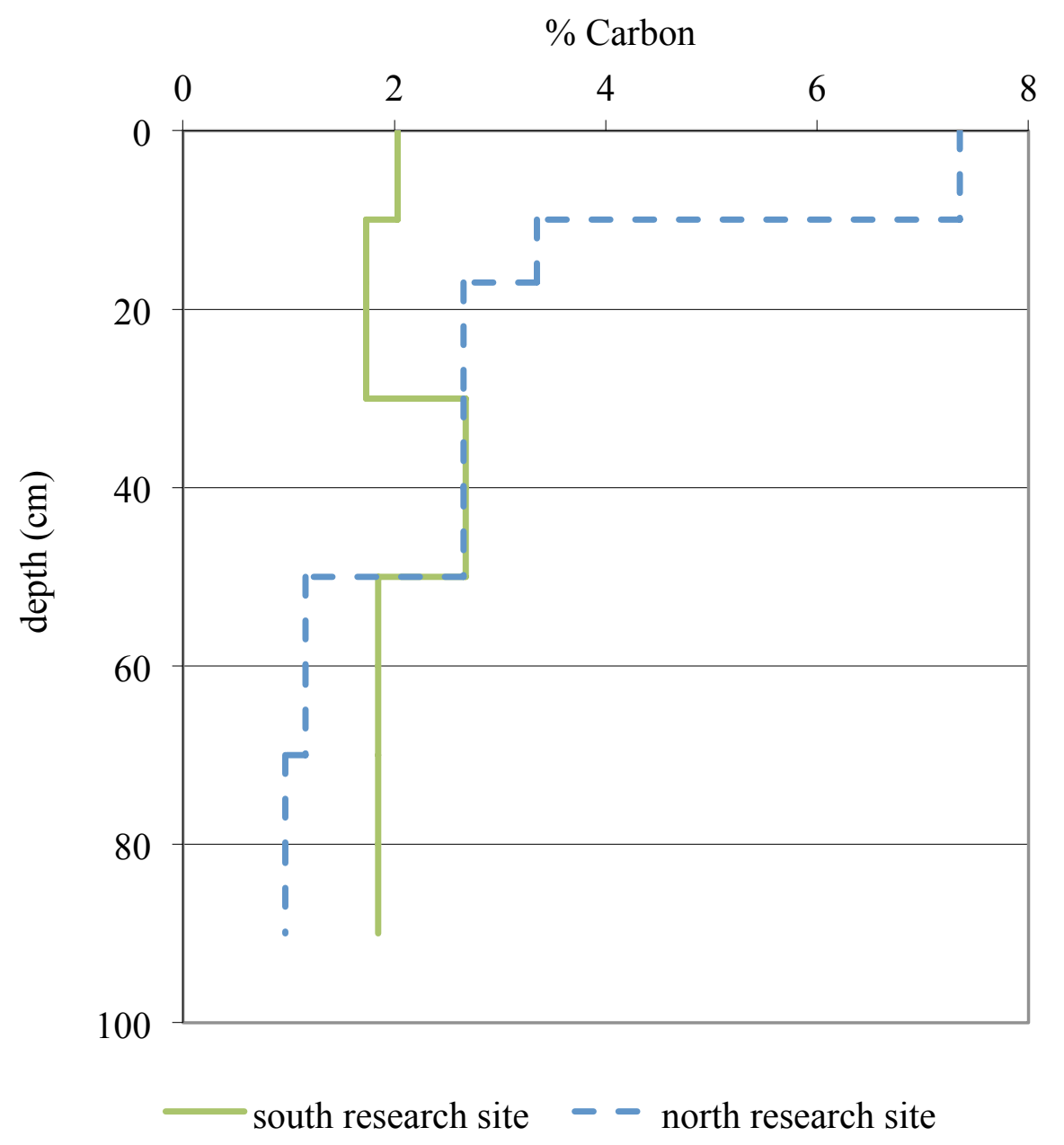

Figure 4-2. Total carbon percentage for soils at the north and south research sites. 


\section{Bulk Density}

Higher values of bulk density usually indicate reduced aeration and decreased hydrologic function including slow water infiltration. Such conditions retain water in the upper portion of the soil profile for longer and are consistent with wetland soil environments. The bulk density values for the soils at the north and south research sites vary from 1.5 to $1.7 \mathrm{~g} \mathrm{~cm}^{-3}$ (Table $4-1 \mathrm{a}$ and Table $4-1 \mathrm{~b}$ ). These values are consistent with the values for loam and clay textured soils, which are the same textures for the soils at the research sites. From these bulk density values, it can reasonably be assumed that water retention can occur for a long enough period of time to create reduced soil conditions.

These conditions were confirmed with volumetric water content measurements (Fig. 3-3a, Fig. 3-3b). To determine saturation, porosity was calculated using bulk density (Table 3-2a, Table 3-2b). The average porosity for the south research site was $41 \%$ and $39 \%$ for the north research site. Therefore, it is expected that a volumetric water content value of approximately $40 \%$ or greater indicates a saturated soil. Both research sites had greater than $40 \%$ volumetric water content which persisted for the length of the study. 


\section{Alternate Indicator of Hydric Soil}

Based upon the data collected, the soils at the north and south research sites met the technical standard, and therefore are hydric. However, neither of these soils meets any of the Field Indicators for Hydric Soil. Therefore, an attempt was made to identify soil morphological features that would be proof positive as a field indicator for these hydric soils located on a slump block geological feature formed from serpentine parent material. Examination of the profile descriptions (Table 4-1a, Table 4-1b) shows that each soil has a horizon within $30 \mathrm{~cm}$ of the surface that lacks a chroma matrix color. In this horizon there is also few or less ( $<2 \%$ of the horizon volume) concentrations of iron oxyhydroxides.

Due to the fact that the soils at the north and south research sites meet the technical standard based on both saturation and IRIS tube analysis, but do not meet a field indicator of hydric soil, an alternate field indicator is proposed in order to accurately identify these soils as hydric (Fig. 4-4). The following indicator is proposed for use with soils located on serpentine parent material with slump block geology:

A layer at least $10 \mathrm{~cm}$ (4 inches) thick, dark color with a value of 2 or less and no chroma, and few or less concentrations. The layer is entirely within $30 \mathrm{~cm}(12$ inches) of the soil surface. 


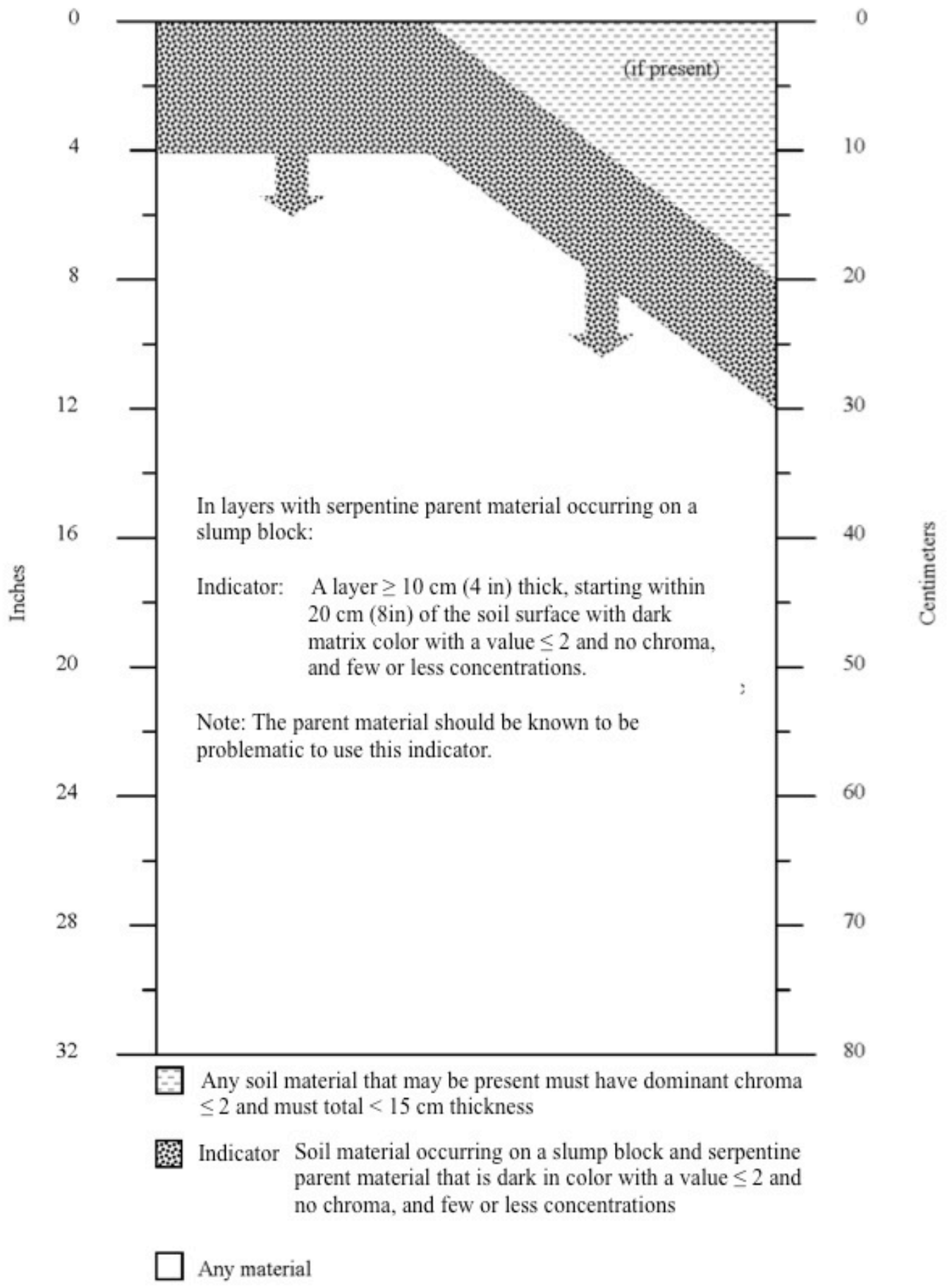

Figure 4-3. Diagram of new test indicator for hydric soils occurring on serpentinitic parent material and slump block geology. 


\section{Conclusions}

The soils at both the north and south research sites are hydric (Chapter 3), however, they do not meet a currently approved Field Indicator of Hydric Soils. Investigations of hydric soils for the purposes of wetland delineation should focus on not only soil morphology, but parent material as well. This study integrated field and laboratory research to address problematic soils derived from serpentine parent material. In the field, reduction resulted from high water table and anaerobic microbial activity in the research sites. Upland sites remained oxidized. Laboratory analyses support the field research that the soils were susceptible to low infiltration rates and high water retention.

This research suggests there is need for an alternate Field Indicator of Hydric Soil to be used specifically in these landscapes on soil formed in serpentine parent materials. Preliminarily, the following is proposed as a new indicator: soils occurring on a slump block and serpentine parent material with a layer at least $10 \mathrm{~cm}$ (4 inches) thick, dark color with a value of 2 or less and no chroma, and few or less concentrations. The layer is entirely within $30 \mathrm{~cm}$ (12 inches) of the soil surface. 


\section{CHAPTER 5 - CONCLUSIONS}

For an area to be classified as a wetland, the site must meet requirements of all three parameters including wetland hydrology, hydrophytic vegetation, and hydric soils (U.S. Army Corps of Engineers, 2008). The north and south research sites discussed in this study meet two of the three parameters necessary for wetland determination. Two primary indicators of wetland hydrology were observed; saturated soil conditions and surface ponding. Additionally, volumetric water content measurements reveal a saturated soil profile throughout the wet season. The research sites meet the standards for hydrophytic vegetation with a prevalence index (PI) of less than 3.0; PI was 1.6 at the south research site and 2.9 at the north research site (U.S. Army Corps of Engineers, 2008). However, these soils do not meet a currently approved Field Indicator of Hydric Soils.

This study integrated field and laboratory research to address problematic soils derived from serpentine parent material. The analysis of IRIS tubes indicated that there are periods during the growing season in which the soils are reduced and anaerobic. The reduction is a result from high water holding capacity due to the clay-rich soil and anaerobic microbial activity shown through the carbon analysis of the research sites. Upland sites showed no signs of reduction including the absence of redox features.

Therefore, despite not meeting an approved Field Indicator, the soils at the north and south research sites are hydric. This research has proven a clear need for a new test Field Indicator to be devised. This new indicator would take into account the serpentine parent material, black soil matrix color, and a slump block landform. 


\section{CHAPTER 6 - FUTURE CONSIDERATIONS}

The National Technical Committee for Hydric Soils (NTCHS) is responsible for the development and guidelines for Field Indicators of Hydric Soils (Vasilas et al., 2010). Indicators are designed to be proof-positive and change periodically as new discoveries are uncovered and more research and field data is collected. Development of a new Field Indicators of Hydric Soils or modifications to existing indicators requires an integrated approach of both field and laboratory research and approval by the NTCHS.

Before a proposal for a new test Indicator of Hydric Soils for serpentinitic soils in a Mediterranean climate along the central coast of California can be submitted, further field data collection is necessary. These data need to include an additional site with similar morphological features to the north and south research sites and neighboring nonhydric site for a total of 3 hydric sites and 3 neighboring nonhydric sites. Both the additional hydric site and nonhydric sites require detailed morphological descriptions and vegetation collection.

Once the test indicator is approved, additional field and data collection is necessary from the six sites in order for the test indicator to be approved as a Field Indicator. These data include updated detailed morphological descriptions and vegetation collection. Saturation/inundation data and redox potential data collected over a period of time in which demonstrates the saturation cycle (wet-dry-wet) of at least one of the hydric sites and one of the nonhydric sites. Precipitation and in-situ soil-water $\mathrm{pH}$ data from the sites should also be included to support the saturation data. 


\section{REFERENCES}

Alexander, E.B., R.G. Coleman, T. Keeler-Wolf, and S.P. Harrison. 2007. Serpentine geoecology of western North America: Geology, soils, and vegetation. Oxford University Press, Inc.

Berkowitz, J.F., and J.B. Sallee. 2011. Investigating problematic hydric soils using hydrology, IRIS tubes, chemistry, and the Hydric Soils Technical Standard. Soil Sci. Soc. Am. J. 75:2379-2385.

Blake, G.R. and K.H. Hartge. 1986. Bulk density. P. 3630382. In A. Klute (ed.) Methods of soil analysis. Part 1. Physical and mineralogical methods. 2nd ed. Agron. Monogr. 9. ASA and SSA, Madison, WI.

Bouyoucos, G.J. 1962. Hydrometer method improved for making particle size analysis of soil. Agron. J. 54:464-465.

Bowen, G.D., and A.D. Rovira. 1999. The rhizosphere and its management to improve plant growth. Adv. Agron. 66:1-102.

Brady, N.C., and R.R. Weil. 2010. Elements of the nature and properties of soils. Pearson Education, Upper Saddle River, New Jersey.

Castenson, K.L., and M.C. Rabenhorst. 2006. Indicator of reduction in soil (IRIS): Evaluation of a new approach for assessing reduced conditions in soil. Soil Sci. Soc. Am. J. 70.4:1222-1226.

Craft, C.B., J.L. Richardson, and M.J. Vepraskas. 2001. Biology of wetland soils. Wetland soils: Genesis, hydrology, landscapes and classification. CRC Press LLC, Boca Raton, Florida.

Elementar Analysensysteme GmbH. 2005. Vario MAX CNS Macro Elemental Analyzer operating instructions. Hanau, Germany.

Fiedler, S., M.J. Vepraskas, and J.L. Richardson. 2007. Soil redox potential: Importance, field measurements, and observations. Adv. Agron. 94:1-54.

Harden, D.H. 2004. California geology. 2nd ed. Pearson Prentice Hall, Upper Saddle River, NJ.

Jenkinson, B. 2003. Indicators of Reduction in Soils (IRIS): A visual method for the identification of hydric soils. Ph.D. diss. Purdue Univ., West Lafayette, IN.

Lee, B.D., R.C. Graham, T.E. Laurent, and C. Amrhein. 2004. Pedogenesis in a wetland meadow and surrounding serpentinitic landslide terrain, northern California, USA. Geoderma 118:303-320. 
Lichvar, R.W. 2012. The national wetland plant list. Cold Reg. Res. Eng. Lab. U.S. Army Corps of Engineers. Hanover, NH.

Mausbach, M.J. 1994. Classification of wetland soils for wetland identification. Soil Surv. Horiz. 35:17-25.

Ministry of Energy and Mines. 2013. Landslide types. Province of British Columbia. http://www.empr.gov.bc.ca/ (accessed 14 Aug. 2014).

Mitsch, W.J., J.G. Gosselink, C.J. Anderson, L. Zhang. 2009. Wetland ecosystems. Wetland ecosystems: vii +295 pp.-vii +295 pp.

Nahlik, A.M., and W.J. Mitsch. 2006. Tropical treatment wetlands dominated by freefloating macrophytes for water quality improvement in Costa Rica. Ecol. Eng. 28:246-257.

Oze, C., C. Skinner, A.W. Schroth, and R.G. Coleman. 2008. Growing up green on serpentine soils: Biogeochemistry of serpentine vegetation in the Central Coast Range of California. Appl. Geochem. 23: 3391-3403.

Rabenhorst, M.C. 2008. Protocol for using and interpreting IRIS tubes. Soil Surv. Horiz. 49:74-77.

Rabenhorst, M.C., and S.N. Burch. 2006. Synthetic iron oxides as an indicator of reduction in soils (IRIS). Soil Sci. Soc. Am. J. 70:1227-1236.

Schoeneberger, P.J. 2002. Field book for describing and sampling soils. V 3.0. U.S. Gov. Print.

Shaffer, P.W., M.E. Kentula and S.E. Gwin. 1999. Characterization of wetland hydrology using hydrogeomorphic classification. Wetlands 19: 490-504.

Soil Survey Staff. 2012. Web soil survey: Soil Data mart. USDA-NRCS. http://websoilsurvey.nrcs. usda.gov/ (accessed 3 Jan. 2014).

Soil Survey Staff. 2010. Keys to soil taxonomy. 11th ed. USDA-NRCS, Washington, DC.

Tanaka, A., M. Ohtani, Y. Suyama, N. Inomata, Y. Tsumura, B.A. Middleton, H. Tachida, and J. Kusumi. 2012. Population genetic structure of a widespread coniferous tree, Taxodium distichum L. Rich. (Cupressaceae) in the Mississippi River Alluvial Valley and Florida. Tree Genet. Genomes 8: 1135-1147.

U.S. Army Corps of Engineers. 2008. Regional supplement to the Corps of Engineers 
wetland delineation manual: arid west region. U.S. Army Eng. Res. Develop. Center. U.S. Gov. Print. Office, Washington, DC.

Vasilas, L.M., G.W. Hurt, and C.V. Noble. 2010. Field indicators of hydric soils in the United States: A guide for identifying and delineating hydric soils. Ver. 7.0. NRCS-USDA, in coop. NTCHS. Washington, DC.

Vaughan, K.L., M.C. Rabenhorst, and B.A. Needleman. 2009. Saturation and temperature effects on the development of reducing conditions in soils. Soil Sci. Soc. Am. J. 73:663-667.

Vepraskas, M.J. 1992. Redoximorphic features for identifying aquic conditions. North Carolina Agric. Res. Ser. Tech. Bull. 301. North Carolina Univ., Raleigh. 
APPENDIX A - PARTICLE SIZE ANALYSIS AND BULK DENSITY DATA

\begin{tabular}{|c|c|c|c|c|c|}
\hline & $\%$ Sand & $\%$ Silt & \% Clay & Texture & Bulk Density $\left(\mathrm{g} / \mathrm{cm}^{3}\right)$ \\
\hline \multicolumn{6}{|c|}{ South research site } \\
\hline A & 40 & 30 & 30 & Clay loam & 1.56 \\
\hline $\mathrm{Bg} 1$ & 35 & 28 & 37 & Clay loam & 1.62 \\
\hline $\mathrm{Bg} 2$ & 30 & 25 & 45 & Clay & 1.51 \\
\hline $\mathrm{Bg} 3$ & 28 & 19 & 53 & Clay & -- \\
\hline \multicolumn{6}{|c|}{ North research site } \\
\hline A1 & 58 & 24 & 18 & Sandy Loam & 1.69 \\
\hline A2 & 42 & 28 & 30 & Clay Loam & 1.59 \\
\hline $\mathrm{AB}$ & 36 & 26 & 38 & Clay Loam & 1.66 \\
\hline Bg1 & 34 & 34 & 32 & Clay Loam & 1.49 \\
\hline $\mathrm{Bg} 2$ & 34 & 14 & 52 & Clay & 1.67 \\
\hline $\mathrm{Bg} 3$ & 33 & 17 & 50 & Clay & -- \\
\hline
\end{tabular}


APPENDIX B - SOIL VOLUMETRIC WATER CONTENT

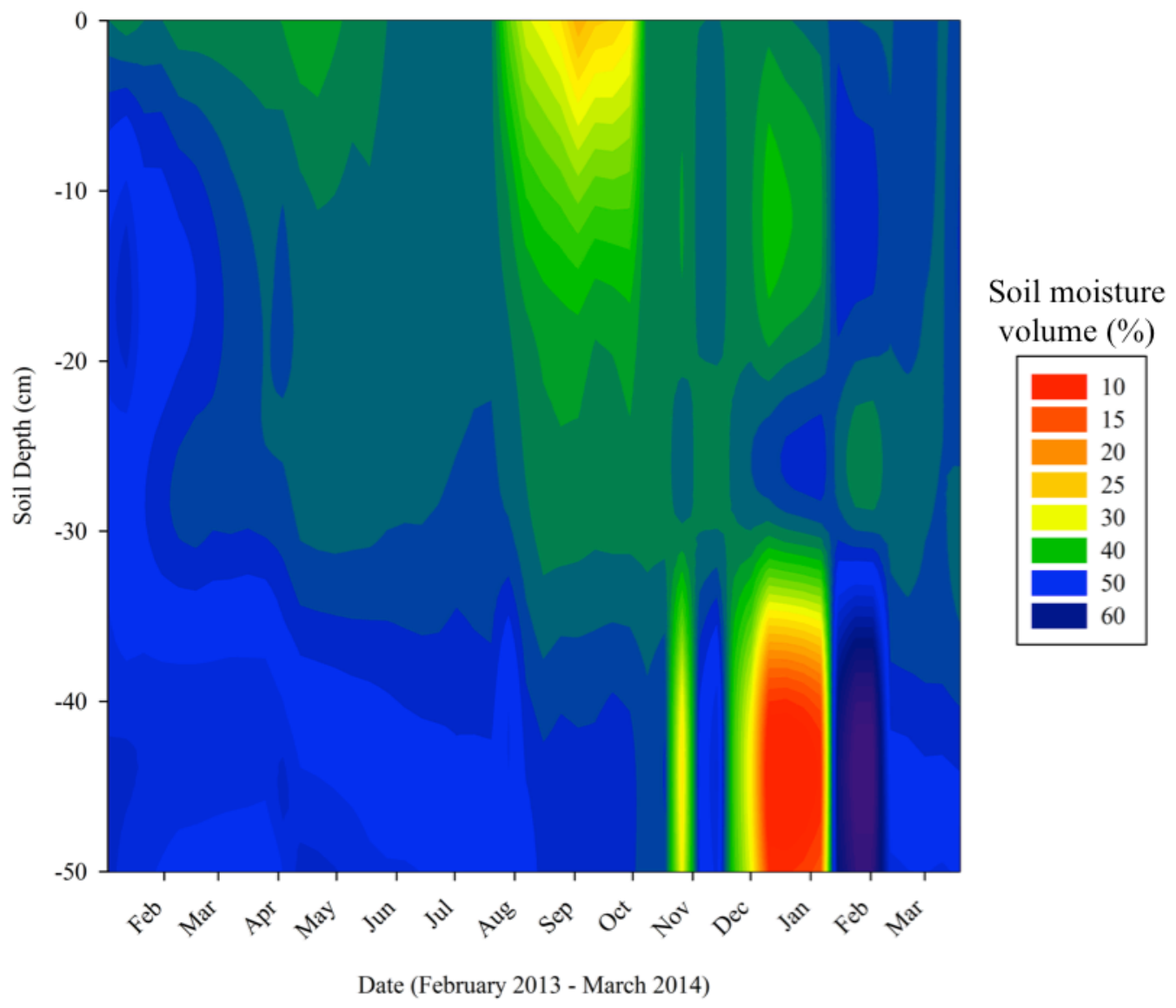

Soil volumetric water content measured at $10,20,3040$, and $50 \mathrm{~cm}$ below the soil surface from February 2013 to March 2014 at the south research site. 


\section{APPENDIX C - SOIL DESCRIPTIONS}

Description of soil at upland near south research site (all colors were recorded moist unless otherwise noted).

\begin{tabular}{ccc}
\hline Horizon & Depth $(\mathbf{c m})$ & Description \\
\hline $\mathrm{A}$ & $0-11$ & Black (10YR 2/1) clay (41\% clay); few, distinct clay films. \\
$\mathrm{Bt} 1$ & $11-22$ & Black (10YR 2/1) clay (41\% clay); few, distinct clay films. \\
$\mathrm{Bt} 2$ & $22-35$ & Black (10YR 2/1) clay (44\% clay); many, prominent clay films. \\
$\mathrm{Bt} 3$ & $35-66$ & Black (10YR 2/1) clay (46\% clay); many, prominent clay films. \\
$\mathrm{Cr}$ & $66-76+$ & --- \\
\hline
\end{tabular}

Description of soil at upland near north research site (all colors were recorded moist unless otherwise noted).

\begin{tabular}{ccc}
\hline Horizon & Depth $(\mathbf{c m})$ & Description \\
\hline $\mathrm{A}$ & $0-10$ & Black (10YR 2/1) loam (25\% clay). \\
$\mathrm{Bt} 1$ & $10-25$ & Black (10YR 2/1) clay loam (35\% clay). \\
$\mathrm{Bt} 2$ & $25-49$ & Very dark brown (10YR 2/2) clay (42\% clay). \\
$\mathrm{BC}$ & $49-61$ & Olive brown (2.5Y 4/3) gravelly clay loam (37\% clay). \\
$\mathrm{Cr}$ & $61-76+$ & --- \\
\hline
\end{tabular}




\section{APPENDIX D - SOIL PROFILE PHOTOS}

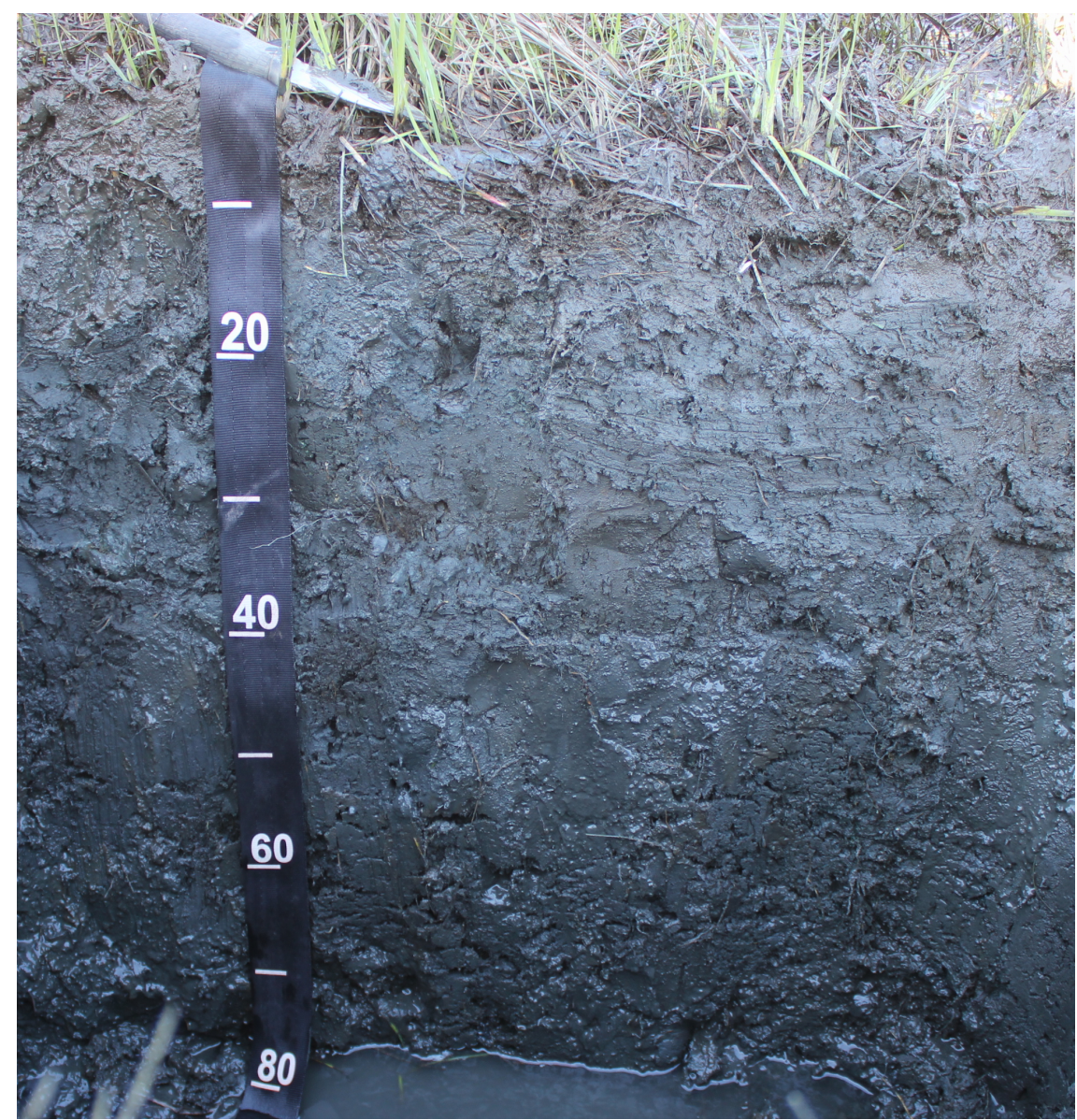

Photo of soil profile at south research site from 0 to $80 \mathrm{~cm}$. 


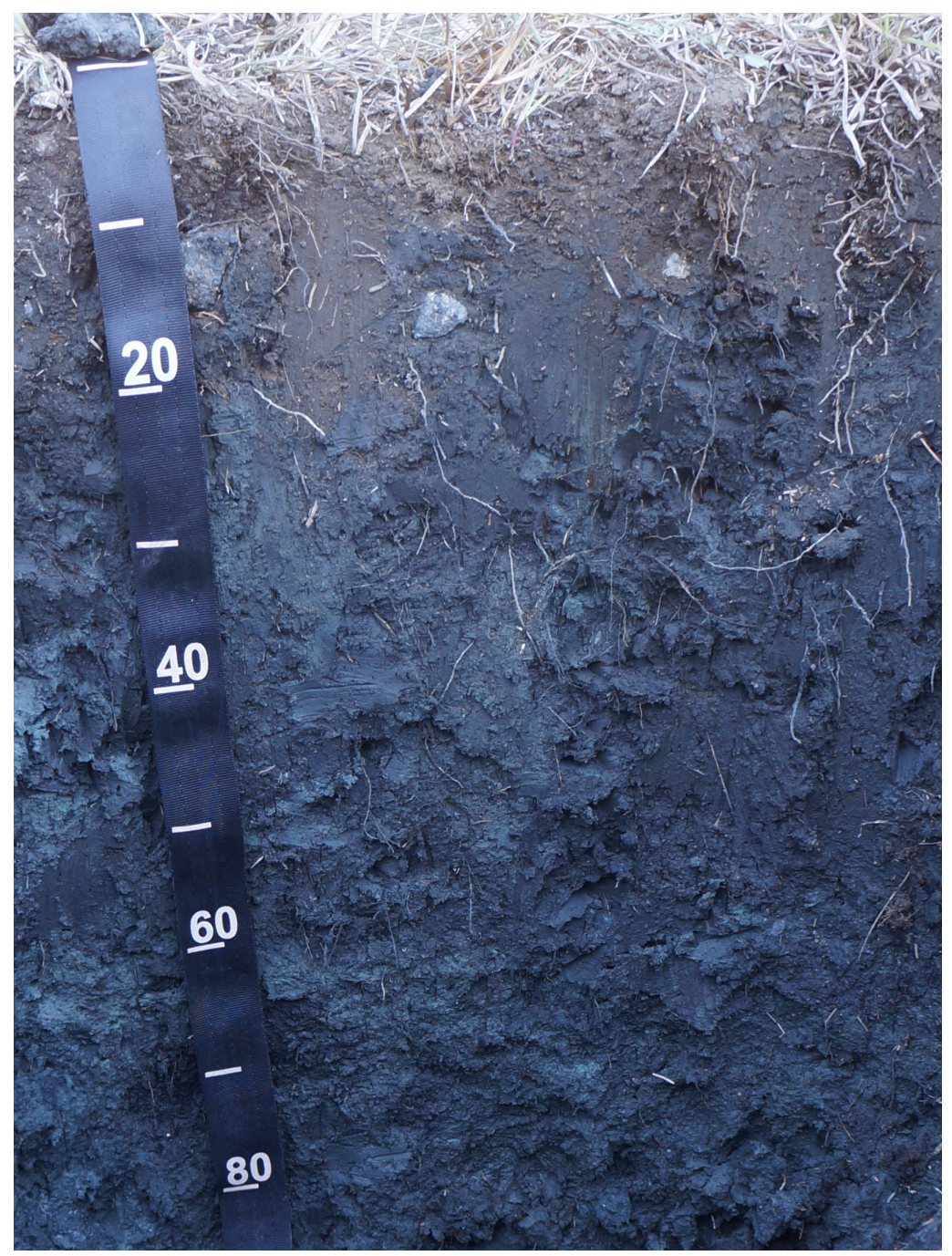

Photo of soil profile at north research site from 0 to $80 \mathrm{~cm}$. 